\title{
2013s-39
}

\section{Exchange rates and commodity prices: measuring causality at multiple horizons}

Hui Jun Zhang, Jean-Marie Dufour, John W. Galbraith

\begin{tabular}{c}
\hline Série Scientifique \\
Scientific Series
\end{tabular}

Montréal

Octobre/October 2013

(C) 2013 Hui Jun Zhang, Jean-Marie Dufour, John W. Galbraith. Tous droits réservés. All rights reserved. Reproduction partielle permise avec citation du document source, incluant la notice $($ ).

Short sections may be quoted without explicit permission, if full credit, including (C) notice, is given to the source.
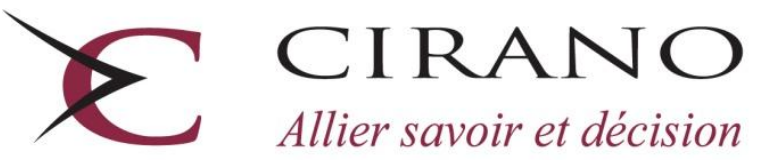

Allier savoir et décision

Centre interuniversitaire de recherche en analyse des organisations 


\section{CIRANO}

Le CIRANO est un organisme sans but lucratif constitué en vertu de la Loi des compagnies du Québec. Le financement de son infrastructure et de ses activités de recherche provient des cotisations de ses organisations-membres, d'une subvention d'infrastructure du Ministère de l'Enseignement supérieur, de la Recherche, de la Science et de la Technologie, de même que des subventions et mandats obtenus par ses équipes de recherche.

CIRANO is a private non-profit organization incorporated under the Québec Companies Act. Its infrastructure and research activities are funded through fees paid by member organizations, an infrastructure grant from the Ministère de l'Enseignement supérieur, de la Recherche, de la Science et de la Technologie, and grants and research mandates obtained by its research teams.

\section{Les partenaires du CIRANO}

\section{Partenaire majeur}

Ministère de l'Enseignement supérieur, de la Recherche, de la Science et de la Technologie

Partenaires corporatifs

Autorité des marchés financiers

Banque de développement du Canada

Banque du Canada

Banque Laurentienne du Canada

Banque Nationale du Canada

Banque Scotia

Bell Canada

BMO Groupe financier

Caisse de dépôt et placement du Québec

Fédération des caisses Desjardins du Québec

Financière Sun Life, Québec

Gaz Métro

Hydro-Québec

Industrie Canada

Investissements PSP

Ministère des Finances et de l'Économie

Power Corporation du Canada

Rio Tinto Alcan

State Street Global Advisors

Transat A.T.

Ville de Montréal

\section{Partenaires universitaires}

École Polytechnique de Montréal

École de technologie supérieure (ÉTS)

HEC Montréal

Institut national de la recherche scientifique (INRS)

McGill University

Université Concordia

Université de Montréal

Université de Sherbrooke

Université du Québec

Université du Québec à Montréal

Université Laval

Le CIRANO collabore avec de nombreux centres et chaires de recherche universitaires dont on peut consulter la liste sur son site web.

Les cahiers de la série scientifique (CS) visent à rendre accessibles des résultats de recherche effectuée au CIRANO afin de susciter échanges et commentaires. Ces cahiers sont écrits dans le style des publications scientifiques. Les idées et les opinions émises sont sous l'unique responsabilité des auteurs et ne représentent pas nécessairement les positions du CIRANO ou de ses partenaires.

This paper presents research carried out at CIRANO and aims at encouraging discussion and comment. The observations and viewpoints expressed are the sole responsibility of the authors. They do not necessarily represent positions of CIRANO or its partners. 


\title{
Exchange rates and commodity prices: measuring causality at multiple horizons
}

\author{
Hui Jun Zhang ${ }^{\dagger}$, Jean-Marie Dufour ${ }^{*}$, John W. Galbraith ${ }^{\S}$
}

\begin{abstract}
Résumé/abstract
Understanding and measuring the relative roles of different causal channels between commodity prices and exchange rates has important implications in financial decision making, especially for market participants with short horizons. From a macroeconomic perspective, this can also be useful for interpreting exchange rate movements, financial market monitoring and monetary policy. Basic economic reasoning on currency demand suggests that the currencies of countries whose exports depend heavily on a particular commodity should be strongly influenced by its price, so commodity price movements should lead (Granger-cause) exchange rate movements (macroeconomic/trade mechanism). In contrast, the present value model of forward-looking exchange rates suggests reverse causation, i.e. exchange rates should Granger-cause commodity prices (expectations mechanism). We examine empirically the causal relationship between commodity prices and exchange rates, using data on three commodities (crude oil, gold, copper) and three countries (Canada, Australia, Chile), over the period 2000-2009. To go beyond pure significance tests of non-causality and to provide a relatively complete picture of the links, measures of the strength of causality for different horizons and directions are estimated and compared. Since lowfrequency data may easily fail to capture important features of the relevant causal links in volatile financial markets - such as foreign exchange and commodity markets - high-frequency (daily and 5-minute) data are exploited. Both unconditional and conditional (given general stock market conditions) causality measures are considered, and allowance for "dollar effects" is made by considering non-U.S. dollar variables. We identify clear causal patterns: (1) Granger causality between commodity prices and exchange rates is visible in both directions; (2) it is stronger at short horizons, and becomes weaker as the horizon increases; (3) causality from commodity prices to exchange rates is stronger than causality in the reverse direction across multiple horizons: the ratios of causality measures in two different directions can be quite high (for example, as high as 5 or 10 in favor of causation from commodity prices to exchange rates), especially at short horizons; (4) eliminating dollar effects weakens causality from exchange rates to commodity prices, and reveals a more definite pattern where causality from commodity prices to exchange rates dominates across multiple horizons. In contrast with earlier results on the non-predictability of exchange rates, we find that the macroeconomic/trade-based mechanism plays a central role in exchange rate dynamics, despite the financial features of these markets.
\end{abstract}

Mots clés : multi-horizon causality; causality measures; commodity prices; exchange rates; stock prices; high-frequency data; spurious causality; financial markets.

Codes JEL : F31, G15, G17.

\footnotetext{
*We thank Abderrahim Taamouti, Jean-Michel Zakoïan, Victoria Zinde-Walsh and Markus Poschke for their valuable comments. This work was supported by the William Dow Chair in Political Economy (McGill University), the Bank of Canada (Research Fellowship), the Toulouse School of Economics (Pierre-de-Fermat Chair of excellence), the Universitad Carlos III deMadrid (Banco Santander deMadrid Chair of excellence), a Guggenheim Fellowship, a Konrad-Adenauer Fellowship (Alexander-von-Humboldt Foundation, Germany), the Canadian Network of Centres of Excellence [program on Mathematics of Information Technology and Complex Systems (MITACS)], the Natural Sciences and Engineering Research Council of Canada, the Social Sciences and Humanities Research Council of Canada, and the Fonds de recherche sur la société et la culture (Québec).

${ }^{\dagger}$ Cambridge-INET Institute, Faculty of Economics, University of Cambridge. Mailing Address: Faculty of Economics, University of Cambridge, Austin Robinson Building, Sidgwick Avenue, Cambridge CB3 9DD, UK.

*William Dow Professor of Economics, McGill University, Centre interuniversitaire de recherche en analyse des organisations (CIRANO), and Centre interuniversitaire de recherche en économie quantitative (CIREQ). Mailing address: Department of Economics, McGill University, Leacock Building, Room 519, 855 Sherbrooke Street West, Montréal, Québec H3A 2T7, Canada. TEL: (1) 5143984400 ext. 09156; FAX: (1) 514398 4800; e-mail: jeanmarie. dufour@ mcgill.ca . Web page: http://www.jeanmariedufour.com

${ }^{\S}$ Chair, Department of Economics, McGill University. Mailing address: Department of Economics, McGill University, Leacock Building, 855 Sherbrooke Street West, Montréal, Québec H3A 2T7, Canada. TEL: (514) 398-4400 ext 09044. Fax: (514) 3984938. e-mail: john.galbraith@mcgill.ca. Web page: http://johngalbraith-economics.mcgill.ca/
} 


\section{Contents}

1. Introduction 1

2. Framework 4

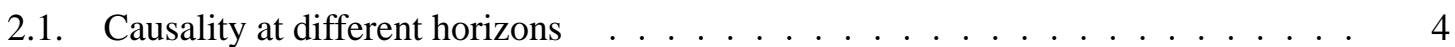

2.2. Measuring causality across horizons . . . . . . . . . . . . . 5

2.3. Causality measures in VARMA models . . . . . . . . . . . . . . 6

3. Empirical results 9

3.1. Data and methodology . . . . . . . . . . . . . . . . . 9

3.2. U.S. dollar-denominated exchange rates . . . . . . . . . . . . . . 10

3.3. Non-U.S. dollar-denominated exchange rates . . . . . . . . . . . . . . . 13

$\begin{array}{lll}\text { 4. Conclusion } & 15\end{array}$ 


\section{List of Tables}

1 Data description . . . . . . . . . . . . . . . . . . . 10

2 Granger non-causality tests - CAD/USD, AUD/USD, CLP/USD . . . . . . 11

3 Granger non-causality tests $-C A D / G B P, C A D(C E R I) \ldots \ldots \ldots \ldots$

4 Granger non-causality tests - AUD/JPY, AUD $(T W I) \ldots \ldots \ldots \ldots$

\section{List of Figures}

1 Unconditional causality measures between CAD/USD and oil price . . . . . . . .

2 Unconditional causality measures between AUD/USD and gold price; between CLP/USD and copper price . . . . . . . . . . . . . . . . . 23

3 Conditional causality measures between CAD/USD, oil price and S\&P500 price (daily) . . . . . . . . . . . . . . . . . . . . . . . 24

4 Conditional causality measures between CAD/USD, oil price and S\&P500 price

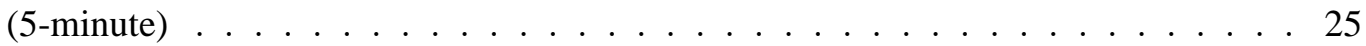

5 Comparison of two directions of causality between CAD/USD, oil price and S\&P500 price . . . . . . . . . . . . . . . . . . 26

6 Conditional causality measures between AUD/USD, gold price and S\&P500 price 27

7 Conditional causality measures between CLP/USD, copper price and S\&P500 price 28

8 Comparison of two directions of causality between AUD/USD, gold price and S\&P500 price; between CLP/USD, copper price and S\&P500 price . . . . . . . . . 29

9 Unconditional causality measures between CAD/GBP and oil price; between CERI and oil price . . . . . . . . . . . . . . . . . . . . . . . . 30

10 Unconditional causality measures between AUD/JPY and gold price; between AUD (TWI) and gold price . . . . . . . . . . . . . . . . . . . . . 31

11 Conditional causality measures between CAD/GBP, oil price and S\&P500 price . 32

12 Conditional causality measures between CERI, oil price and S\&P500 price . . . . 33

13 Comparison of two directions of causality between CAD/GBP, oil price and S\&P500 price; between CERI, oil price and S\&P500 price . . . . . . . . . . . . 34

14 Conditional causality measures between AUD/JPY, gold price and S\&P500 price . 35

15 Conditional causality measures between AUD (TWI), gold price and S\&P500 price 36

16 Comparison of two directions of causality between AUD/JPY, gold price and S\&P500 price; between AUD (TWI), gold price and S\&P500 price . . . . . . . . . 37 


\section{Introduction}

The dynamic relationship between commodity prices and exchange rates has attracted much attention from both researchers and practitioners. Two main explanations have been proposed. The first one suggests that changes in a commodity price lead to changes in the exchange rate of the corresponding commodity currency. This idea commonly appears in both the research literature [see, for example, Chen and Rogoff (2003) and Chen (2004)] and press commentaries. ${ }^{1}$ The second explanation stresses the financial and speculative features of foreign exchange markets: exchange rates can help predict economic fundamentals including commodity prices; see, for example, Meese and Rogoff (1983), Engel and West (2005), Cheung, Chinn and Pascual (2005), Rogoff and Stavrakeva (2008), Chen, Rogoff and Rossi (2010) and Rossi (2013). Following the first mechanism, commodity prices should help predict exchange rate movements. According to the second one, the reverse should happen. Thus, a central difference between these two alternative explanations lies in the direction of causality in the sense of Wiener-Granger.

The first theory relies on macroeconomic and trade-theory arguments. For a small open economy whose exports depend heavily on a particular commodity (for example, gold for Australia, crude oil for Canada, copper for Chile), an increase in the price of an important export commodity should produce an upward pressure on the demand for its currency, which leads to an appreciation of the currency. For instance, while crude oil is the largest Canadian export, Canada's total crude oil production is a small share of world output. The price of oil is determined by global supply and demand conditions to which Canada contributes only modestly, while a change in the price of oil has a large effect on the value of Canadian exports. This mechanism can be justified in sticky-price open economy models with non-traded goods, a portfolio-balance model, and the term-of-trade hypothesis; see Chen and Rogoff (2003) and Chen (2004). This type of explanation suggests that exchange rate movements can be predicted by economic variables. However, statistical evidence shows it is generally difficult to forecast exchange rates, so economic models of exchange rate determination do not fare well from the empirical viewpoint. ${ }^{2}$

Instead, according to the second theory, exchange rates are determined - like most asset prices by the net present value of fundamentals (including commodity prices), which implies that exchange rates should lead and therefore Granger-cause commodity prices; see Obstfeld and Rogoff (1996), Engel and West (2005), Chen et al. (2010) and Alquist, Kilian and Vigfusson (2012). ${ }^{3}$

In this paper, we examine empirically the causal relationship between commodity prices and

\footnotetext{
${ }^{1}$ For example, David Parkinson writes in the Globe and Mail (Report on Business, 10 April 2010, B14): "When analyzing the loonie, always look at oil"; "loonie" is a colloquialism for the Canadian dollar, a reference to the image of a loon on the coin. In Bloomberg Businessweek (April 18, 2013), Sebastian Boyd states: "Chilean Peso declines as principal export copper reaches new low". In the Wall Street Journal (July 5, 2013), Vincent Cignarella writes: “... a rise in the price of the precious metal would do wonders to boost the fortunes of the Australian dollar". In Bloomberg News (February 25, 2013), Mariko Ishikawa has an article with title "Australian dollar advances as gold prices increase".

${ }^{2}$ For more general discussions of the theory and empirical evidence on exchange rate markets, the reader may consult Levich (1985), Baillie and McMahon (1989), Frankel and Rose (1995), Froot and Rogoff (1995), Isard (1995), Obstfeld and Rogoff (1996), Mark (2001), Sarno and Taylor (2002) and Kilian and Taylor (2003).

${ }^{3}$ For work on forecasting commodity prices (especially energy prices), see also Schwartz (1997), Schwartz and Smith (2000), Pindyck (2001), Hamilton and Herrera (2004), Tabak and Cajueiro (2007), Hamilton (2009), Kilian (2009), Bernard, Dufour, Khalaf and Kichian (2012), and the references therein.
} 
nominal exchange rates, using data on three commodities (crude oil, gold, copper) and three countries (Canada, Australia, Chile), over the period 2000-2009. We emphasize five issues which should be taken into account in such a study.

First, predictability and dynamic responses may depend on the time horizon, so it is important to assess the patterns of these links across different horizons. In particular, looking at multiplehorizon causality does allow one to account for indirect causal links - which go through different variables across time - and eventually eliminate spurious findings of causation; see Dufour and Renault (1998).

Second, given that causal links may theoretically exist in all directions, it is of interest to determine which links - in terms of direction and time horizon - matter most. This can be done by associating measures with different causal links. More generally, significance tests (for noncausality) are inappropriate for that purpose: it is well known that a large effect (from an economic viewpoint) may not be statistically significant because the data do not allow one to measure it precisely (e.g., due a multicollinearity or a small size), and an economically negligible effect may be statistically significant because the effect, while small, can be very precisely estimated. It is much more informative to parameterize the relevant effects, compute point estimates for these parameters, and eventually confidence sets; see Dufour and Taamouti (2010) and Dufour, Garcia and Taamouti (2012). Non-causality tests can provide evidence of the presence or absence of forecast improvements available from inclusion of the past of other variables, but do not indicate the magnitudes of forecast improvements.

Third, the proposed measures should be intuitive and easy to interpret without a highly restrictive parametric model, possibly as a descriptive device. In particular, they should allow for a wide spectrum of dynamic structures, such as relatively general VAR or VARMA models. For that purpose, we will use here the approach developed in Dufour and Taamouti (2010) and Dufour et al. (2012).

Fourth, it is well known that Granger causality is generally not invariant to aggregation: highfrequency data may reveal patterns which are aggregated away in low-frequency data, and causality in low-frequency data can also be spurious; see Tiao and Wei (1976), Wei (1982, 1990), Marcellino (1999), Breitung and Swanson (2002), and Silvestrini and Veredas (2008). Indeed, as stressed in Dufour and Renault (1998), the interpretation of Granger causality depends on the forecast horizon and data frequency. Data on commodity prices and exchange rates are originally generated at very high frequency. Quarterly data typically used in macroeconomic studies are obtained by aggregating high-frequency data over time. Spurious causality can be induced when intervals between microeconomic decisions of economic agents are finer than those between sample observations.

Fifth, commodity prices and exchange rates are set in highly active financial markets. Movements in such markets can be quite fast or short-lived, so low-frequency data may easily fail to capture causal links. Indeed, the speculative nature of exchange rate markets along with "efficient market" arguments suggest that exchange rates may be difficult to forecast, especially at low frequencies. Understanding and measuring the relative roles of different causal channels between commodity prices and exchange rates at high frequencies has important implications in financial decision making, especially for market participants with short horizons. From a macroeconomic perspective, this can also be useful for interpreting short-run movements of exchange rates, in view 
of monitoring financial markets and monetary policy. In this context, it is also crucial that forecast horizons be taken into account, as well as the quantitative importance of whatever predictability may exist.

No earlier study of the behavior of exchange rates meets these objectives. The closest papers include studies of the relationship between real exchange rates based on real commodity prices based on low-frequency (e.g., quarterly) data; see Gruen and Wilkinson (1994), Amano and van Norden (1995, 1998a), Amano and van Norden (1998b), Chen and Rogoff (2003), Cashina, Ceśpedesb and Sahay (2004), Issa, Lafrance and Murray (2008). Significance tests of the predictive relationship between nominal exchange rates and commodity prices (including tests of conventional Granger non-causality) are also reported by Chen (2004), Chen et al. (2010), Alquist et al. (2012), and Ferraro, Rogoff and Rossi (2012). In all cases, the above studies remain limited to one horizon, without causality measures.

In this paper, we present an empirical study which simultaneously addresses the issues raised above. We examine the causal relationship between commodity prices and nominal exchange rates for three commodity currencies (Canada, Australia, Chile) and three commodity spot prices (crude oil, copper and gold), using daily data (and 5-minute data, for Canada). In view of the incomplete nature of causality at only one horizon, we study and compare causality at different horizons as proposed in Dufour and Renault (1998) and Dufour, Pelletier and Renault (2006). Further, to avoid the overly simplifying features of pure significance tests for non-causality, we compute measures at many horizons because they allow one to assess in a much more precise way the underlying linkages when causality at different horizons in different directions is present. The measures used are based on the concepts and statistical methodology - including both point estimates (of causality measures) and confidence intervals - described in Dufour and Taamouti (2010) for a general time-series framework, and Dufour et al. (2012) in the context of high-frequency data (as in this paper). In particular, the statistical setup we consider allows for general assumptions, such as stationary invertible vector autoregressive moving average (VARMA) models. Both unconditional and conditional (given stock price movements) measures are considered.

We use the price of a single dominant exporting commodity for each country instead of a country-specific commodity index used in Chen et al. (2010), and we include an indicator of the level of equity prices, the S\&P500 index, in conditional causality examinations. As an index pertaining to an important financial asset class which may have causal links with both exchange rates and commodity prices, the S\&P500 index is a potential vehicle for transmission of indirect causality between the variables of interest. Another reason to consider the S\&P500 index is that the connection of stock prices to exchange rates and commodity prices has great interest for both financial researchers and practitioners; see, for example, Kilian (2008) and Kilian and Park (2009)).

Further, it is well known that there can be causal effects of U.S. dollar-denominated exchange rates on commodity prices denominated in U.S. dollars, due to changes in the value of the U.S. dollar. We refer such effects as U.S. dollar-denomination effects or simply "dollar effects". To avoid attributing the causal effects to this source, we use two alternative currency benchmarks: British Pound and Japanese Yen, as well as the effective rates of commodity currencies.

Overall, our results indicate clear causal patterns: (1) Granger causality between commodity prices and exchange rates is visible in both directions; (2) it is stronger at short horizons, and be- 
comes weaker as the horizon increases; (3) causality from commodity prices to exchange rates (macroeconomic/trade mechanism) is stronger than causality in the reverse direction (expectations mechanism) across multiple horizons; (4) the ratios of causality measures in two different directions can be quite high (for example, as high as 5 or 10 in favor of causation from commodity prices to exchange rates), especially at short horizons; (5) eliminating dollar effects weakens causality from exchange rates to commodity prices, and reveals a more definite pattern where causality from commodity prices to exchange rates is stronger than causality in the reverse direction, across multiple horizons. In contrast with earlier results on the non-predictability of exchange rates, our results suggest that the macroeconomic/trade-based mechanism plays a central role in exchange rate dynamics, despite the financial features of these markets. However, to "observe" the economic effects of commodity prices on exchange rates, it is important to consider high data frequencies and to use an appropriate causal methodology.

Section 2 introduces the framework we use, involving the statistical concepts of multi-horizon causality and measures. Section 3 gives a detailed description of data used in this study and reports and discusses the empirical results. Section 4 concludes.

\section{Framework}

The main objective of this paper is to examine high-frequency causality between commodity prices and exchange rates using daily and intra-day data. In this section, we introduce the statistical concepts of multi-horizon causality and causality measures that we use.

\subsection{Causality at different horizons}

Granger (1969) introduced the concept of causality in terms of predictability at horizon one of a (vector) variable $X$ from its own past, the past of another (vector) variable $Y$, and possibly a vector $Z$ of auxiliary variables; this has come to be known as Granger causality. This concept has become a fundamental notion for studying dynamic relationships among time series. An important extension was proposed by Dufour and Renault (1998) who generalized the notion of Granger causality by considering linear causality at a given (arbitrary) horizon $h$ and derived necessary and sufficient conditions for non-causality between variables up to any given horizon $h(1 \leq h \leq \infty)$, allowing the possibility of indirect causality. This indirect causality in the presence of auxiliary variables can be used to distinguish short-run and long-run (non)causality: for example, although $Y$ does not Granger-cause $X$ at horizon one, it may nonetheless help to predict $X$ several periods ahead though transmission by a vector $Z$ of auxiliary variables. The importance of the distinction between correlation and causality is also underscored when considering horizons longer than one period.

Dufour and Renault (1998) defined linear causality at any given horizon $h \geq 1$ in terms of orthogonality between subspaces of a Hilbert space of random variables with finite second moments. We will adopt the notation used in Dufour and Taamouti (2010). We denote by $L^{2}$ a Hilbert space of real random variables with finite second moments. Define the "reference information set" $I=$ $\{I(t): t \in \mathbb{Z}, t>\omega\}$ and $t<t^{\prime} \Rightarrow I(t) \subseteq I\left(t^{\prime}\right)$ for all $t>\omega$, where $I(t)$ is defined on Hilbert subspace of $L^{2}, \omega \in \mathbb{Z} \cup\{-\infty\}$ represents a "starting point", and $\mathbb{Z}$ is the set of the integers. Let $H$ 
be a (possibly empty) Hilbert subspace of $L^{2}$, which contains information common to all $I(t)$ [e.g., the constant in a regression model], and assume $H \subseteq I(t)$. Consider three multivariate stochastic processes: $X=\{X(t): t \in \mathbb{Z}, t>\omega\}, Y=\{Y(t): t \in \mathbb{Z}, t>\omega\}$ and $Z=\{Z(t): t \in \mathbb{Z}, t>\omega\}$, where $X(t)=\left(x_{1}(t), \ldots, x_{m_{1}}(t)\right)^{\prime}, Y(t)=\left(y_{1}(t), \ldots, y_{m_{2}}(t)\right)^{\prime}, Z(t)=\left(z_{1}(t), \ldots, z_{m_{3}}(t)\right)^{\prime}$, with numbers of components $m_{1} \geq 1, m_{2} \geq 1, m_{3} \geq 0$, and $x_{i}(t), y_{i}(t), z_{i}(t) \in L^{2}$, for all $i$. Denote by $X(\omega, t], Y(\omega, t]$ and $Z(\omega, t]$ the Hilbert spaces spanned by the components of variables $X, Y$ and $Z$ respectively up to time $t$. Then information sets $I_{X}(t)$ and $I_{X Y}(t)$ are defined as $I_{X}(t)=I(t)+X(\omega, t]$ and $I_{X Y}(t)=I(t)+X(\omega, t]+Y(\omega, t]$, and $Z(\omega, t]$ is assumed to be included in $I(t)$.

For any information set $B(t)$ (some Hilbert subspace of $L^{2}$ ), given a positive integer $h$, we denote by $P[X(t+h) \mid B(t)]$ the best linear forecast of $X(t+h)$ based on the information set $B(t)$, by

$$
U_{L}[X(t+h) \mid B(t)]=X(t+h)-P[X(t+h) \mid B(t)]
$$

the corresponding linear forecast error, and by

$$
\Sigma[X(t+h) \mid B(t)]=\mathrm{E}\left\{U_{L}[X(t+h) \mid B(t)] U_{L}^{\prime}[X(t+h) \mid B(t)]\right\}
$$

the variance-covariance matrix of the linear forecast error (or mean squared error, MSE). Thus we have the following definition of non-causality at any given horizon $h \geq 1$ [see Dufour and Renault (1998) and Dufour and Taamouti (2010)].

Definition 2.1 NON-CAUSAlity AT HORIZON $h . \quad Y$ does not cause $X$ at horizon $h$ given $I$, denoted $Y \underset{h}{\rightarrow} X \mid I$, iff

$$
P\left[X(t+h) \mid I_{X}(t)\right]=P\left[X(t+h) \mid I_{X Y}(t)\right] .
$$

We can define non-causality from $X$ to $Y$ at horizon $h$ similarly. This definition concerns the conditional non-causality with auxiliary variables, which may transmit indirect causality between variables at horizons higher than one, even if there is no direct causality at horizon one. If $Z$ is dropped from the information set $\left(m_{3}=0\right)$, then the above definition represents unconditional noncausality. In the absence of auxiliary variables, unconditional non-causality at horizon one implies non-causality at any horizon $h$ (which can be unbounded); see Dufour and Renault (1998).

\subsection{Measuring causality across horizons}

Rejecting non-causality hypotheses in statistical tests implies that certain variables can help in forecasting others [Dufour et al. (2006)]. Of course, statistical significance depends on the data sets and test power, and the outcomes of such tests do not represent the magnitude of causality. Geweke $(1982,1984)$ interpreted causality measures as the proportional reduction in the forecast error variance of a variable available by taking into account the past of other variables. Dufour and Taamouti (2010) make multi-horizon extensions of such measures in the context of a set of linear invertible processes (including VAR, VMA, and VARMA). The latter authors note that "building causality measures at different horizons, along with associated confidence intervals, can yield a much more informative analysis of Granger causality than tests of non-causality."

Following Dufour and Taamouti (2010), we measure causality at horizon $h \geq 1$ as follows. 
Definition 2.2 Causality measure at horizon $h$. For $h \geq 1$,

$$
C_{L}(Y \underset{h}{\rightarrow} X \mid I)=\ln \left[\frac{\operatorname{det}\left\{\Sigma\left[X(t+h) \mid I_{X}(t)\right]\right\}}{\operatorname{det}\left\{\Sigma\left[X(t+h) \mid I_{X Y}(t)\right]\right\}}\right]
$$

is the mean-square causality measure from $Y$ to $X$ at horizon $h$, given $I$.

A causality measure from $X$ to $Y$ at horizon $h$ is defined in a similar way. For $m_{1}=m_{2}=1$, the above definition reduces to

$$
C_{L}(Y \underset{h}{\rightarrow} X \mid I)=\ln \left[\frac{\sigma^{2}\left[X(t+h) \mid I_{X}(t)\right]}{\sigma^{2}\left[X(t+h) \mid I_{X Y}(t)\right]}\right] .
$$

This definition allows for conditional causality with auxiliary variables. If $Z$ is empty $\left(m_{3}=0\right)$, Definition 2.2 defines an unconditional causality measure. This causality measure is nonnegative, and zero if and only if there is no causality at the horizon considered; the higher the value of the measure, the stronger is the causal relationship. When non-causality tests are rejected in both directions, causality may nonetheless be much stronger in one direction, the feature revealed by causality measures. Furthermore, confidence intervals for causality measures can provide more powerful tests for non-causality at any given horizon, and help determine how long the causal effects will last.

\subsection{Causality measures in VARMA models}

We now describe parametric representations of causality measures in the context of linear invertible VARMA models of finite order, which will be used in the empirical analyses below. For simplicity, we assume $X(t)$, and $Y(t)$ are univariate processes $\left(m_{1}=m_{2}=1\right)$. The discrete $m \times 1$ vector process with zero mean $W(t)=(X(t), Y(t), Z(t))^{\prime}$ is characterized by a stationary and invertible $\operatorname{VARMA}(p, q)$ model,

$$
W(t)=\sum_{i=1}^{p} \phi_{i} W(t-i)+\sum_{j=1}^{q} \varphi_{j} u(t-j)+u(t)
$$

where $u(t)$ is a i.i.d. random variable with $\mathrm{E}[u(t)]=0, \mathrm{E}[u(t) u(s)]=\Sigma_{u}$ for $t=s$, and is 0 for $t \neq s$. Hereafter, we call $W(t)$ the unconstrained model. The information sets are defined as above.

To measure causality from $Y$ to $X$ at horizon $h$, we need to know the structure of the marginal process $W_{0}(t)=(X(t), Z(t))^{\prime}$, which follows a stationary $\operatorname{VARMA}(\bar{p} \leq m p, \bar{q} \leq(m-1) p+q)$ :

$$
W_{0}(t)=\sum_{i=1}^{\bar{p}} \bar{\phi}_{i} W_{0}(t-i)+\sum_{j=1}^{\bar{q}} \bar{\varphi}_{j} e(t-j)+e(t)
$$

where $\mathrm{E}[e(t)]=0, \mathrm{E}[e(t) e(s)]=\Sigma_{e}$ for $t=s$, and 0 for $t \neq s$; see Lütkepohl (1993). Hereafter, we call $W_{0}(t)$ the constrained model. 
Under stationarity, $W(t)$ has a $\operatorname{VMA}(\infty)$ representation,

$$
W(t)=\sum_{j=0}^{\infty} \psi_{j} u(t-j)
$$

where $\psi_{j}$ can be represented by the function of $\phi_{i=1, \ldots p}$ and $\varphi_{j=1, \ldots q}$. The linear forecast error of $W(t+h)$ and its variance-covariance matrix are given by

$$
\begin{gathered}
U_{L}\left[W(t+h) \mid I_{W}(t)\right]=\sum_{j=0}^{h-1} \psi_{j} u(t+h-j), \\
\Sigma\left[W(t+h) \mid I_{W}(t)\right]=\sum_{j=0}^{h-1} \psi_{j} \mathrm{E}\left[u(t+h-j) u^{\prime}(t+h-j)\right] \psi_{j}^{\prime}=\sum_{j=0}^{h-1} \psi_{j} \Sigma_{u} \psi_{j}^{\prime} .
\end{gathered}
$$

Then the unconstrained MSE for the linear forecast of $X(t+h)$ is

$$
\sigma^{2}\left[X(t+h) \mid I_{W}(t)\right]=\sum_{j=0}^{h-1} J_{1} \psi_{j} \Sigma_{u} \psi_{j}^{\prime} J_{1}^{\prime}
$$

where $J_{1}=\left[\begin{array}{lll}1 & 0 & 0\end{array}\right]$. Similarly, the constrained model (2.3) can be written as a VMA( $\left.\infty\right)$ model,

$$
W_{0}(t)=\sum_{j=0}^{\infty} \bar{\psi}_{j} e(t-j)
$$

and the forecast error for the linear forecast of $W_{0}(t+h)$ and its variance-covariance matrix are then given by:

$$
\begin{gathered}
U_{L}\left[W_{0}(t+h) \mid I_{W_{0}}(t)\right]=\sum_{j=0}^{h-1} \bar{\psi}_{j} e(t+h-j) \\
\Sigma\left[W_{0}(t+h) \mid I_{W_{0}}(t)\right]=\sum_{j=0}^{h-1} \bar{\psi}_{j} \mathrm{E}\left[e(t+h-j) e^{\prime}(t+h-j)\right] \bar{\psi}_{j}^{\prime}=\sum_{j=0}^{h-1} \bar{\psi}_{j} \Sigma_{e} \bar{\psi}_{j}^{\prime} .
\end{gathered}
$$

Thus the constrained MSE for the linear forecast of $X(t+h)$ is

$$
\sigma^{2}\left[X(t+h) \mid I_{W_{0}}(t)\right]=\sum_{j=0}^{h-1} J_{0} \bar{\psi}_{j} \Sigma_{e} \bar{\psi}_{j}^{\prime} J_{0}^{\prime}
$$

where $J_{0}=\left[\begin{array}{ll}1 & 0\end{array}\right]$. Consequently, the causality measure from $Y$ to $X$ at horizon $h$ can be represented by

$$
C_{L}(Y \underset{h}{\rightarrow} X \mid I)=\ln \left[\frac{\sigma^{2}\left[X(t+h) \mid I_{W_{0}}(t)\right]}{\sigma^{2}\left[X(t+h) \mid I_{W}(t)\right]}\right]=\ln \left[\frac{\sum_{j=0}^{h-1} J_{0} \bar{\psi}_{j} \Sigma_{e} \bar{\psi}_{j}^{\prime} J_{0}^{\prime}}{\sum_{j=0}^{h-1} J_{1} \psi_{j} \Sigma_{u} \psi_{j}^{\prime} J_{1}^{\prime}}\right]
$$

To estimate the causality measure consistently without using maximum likelihood or nonlinear 
least squares, which involve complicated nonlinear optimization and are therefore difficult to use in the context of bootstrap inference procedures, we use the linear estimation approach proposed in Dufour and Taamouti (2010).

Under the assumption that $W(t)$ is invertible, it can be written as an infinite autoregressive process:

$$
W(t)=\sum_{i=1}^{\infty} \pi_{i} W(t-i)+u(t) .
$$

Given a realization $\{W(1), \ldots, W(T)\}$, we can approximate (2.13) by a finite-order VAR $(k)$ model, where $k$ depends on the sample size $T$ :

$$
W(t)=\sum_{i=1}^{k} \pi_{i k} W(t-i)+u_{k}(t) .
$$

The least-squares estimators of the coefficients of the fitted $\operatorname{VAR}(k)$ model and variance-covariance matrix of the error term are denoted as $\hat{\pi}_{i k}$ and $\hat{\Sigma}_{u \mid k}$ respectively. Under general conditions, $W_{0}(t)$ has a $\operatorname{VAR}(\infty)$ representation:

$$
W_{0}(t)=\sum_{i=1}^{\infty} \bar{\pi}_{i} W_{0}(t-i)+e(t)
$$

Model (2.15) can also be approximated by a a finite-order $\operatorname{VAR}(k)$ model, where $k$ depends on the sample size $T$ :

$$
W_{0}(t)=\sum_{i=1}^{k} \bar{\pi}_{i k} W_{0}(t-i)+e_{k}(t) .
$$

The least-squares estimators of the coefficients of the fitted $\operatorname{VAR}(k)$ model and variance-covariance matrix of the error term are denoted as $\tilde{\pi}_{i k}$ and $\tilde{\Sigma}_{e \mid k}$ respectively. Then an estimator of the causality measure from $Y$ to $X$ at horizon $h$ is given by

$$
\hat{C}_{L}(Y \underset{h}{\rightarrow} X \mid I)=\ln \left[\frac{\sum_{j=0}^{h-1} J_{0} \tilde{\Psi}_{j k} \tilde{\Sigma}_{e \mid k} \tilde{\psi}_{j k}^{\prime} J_{0}^{\prime}}{\sum_{j=0}^{h-1} J_{1} \hat{\psi}_{j k} \hat{\Sigma}_{u \mid k} \hat{\psi}_{j k}^{\prime} J_{1}^{\prime}}\right]
$$

where $\hat{\psi}_{j k}$, the estimator of $\psi_{j}$, can be calculated using $\hat{\pi}_{i k}$, and $\tilde{\psi}_{j k}$ can be obtained in a similar way; see Dufour and Taamouti (2010), who also proved the consistency and asymptotic normality of this estimator of the causality measure. That is,

$$
T^{1 / 2}\left[\hat{C}_{L}(Y \underset{h}{\rightarrow} X \mid I)-C_{L}(Y \underset{h}{\rightarrow} X \mid I)\right] \stackrel{d}{\rightarrow} N\left[0, \sigma_{c}^{2}(h)\right]
$$

where $\sigma_{c}^{2}(h)=D_{C} \Omega D_{C}^{\prime}, D_{C}=\partial C_{L}(Y \underset{h}{\rightarrow} X \mid I) / \partial \theta^{\prime}, \theta=\left(\operatorname{vec}(\pi)^{\prime}, \operatorname{vech}\left(\Sigma_{u}\right)^{\prime}\right)^{\prime}, \Omega$ is the asymptotic variance-covariance matrix of $\hat{\theta}$, vec denotes the column stacking operator, and vech is the column stacking operator that stacks the elements on and below the diagonal only. In the empirical implementation below, we estimate the unconditional and conditional causality measures up to 
horizon 15, based on (2.17), where the value of $k$ is chosen according to the Akaike information criterion (AIC) as suggested by Lewis and Reinsel (1985).

As noted in Dufour and Taamouti (2010), analytical differentiation of the causality measures with respect to $\theta$ is very difficult, so a bootstrap approach is a better choice. We therefore use the eight-step residual-based bootstrap method proposed in Dufour and Taamouti (2010) to compute the confidence interval of the causality measure at given horizon $h$. The asymptotic validity of the residual-based bootstrap $\hat{C}_{L}^{*}(Y \underset{h}{\rightarrow} X \mid I)$ is proven in proposition 8.2 in Dufour and Taamouti (2010):

$$
T^{1 / 2}\left[\hat{C}_{L}^{*}(Y \underset{h}{\rightarrow} X \mid I)-\hat{C}_{L}(Y \underset{h}{\rightarrow} X \mid I)\right] \stackrel{d}{\rightarrow} N\left[0, \sigma_{c}^{2}(h)\right]
$$

where $\sigma_{c}^{2}(h)$ is defined as above.

\section{Empirical results}

In this section, we first describe data, and then report the empirical results of non-causality tests and numerical measures of the magnitude of a causal effect at multiple horizons. Because our aim is to identify general patterns rather than to examine a single specific case, we present results on multiple currencies and methods of treating the data. Many of the results are given graphically in order to synthesize a large body of evidence in a relatively convenient format. We first present the detailed results, and then summaries of key observations. Accounting for dollar effects turns out to be an important element in understanding the effects, and these results are therefore collected and discussed separately.

\subsection{Data and methodology}

We consider three commodity-exporting, small open economies with floating exchange rates: Canada, Australia and Chile. We use data on nominal exchange rates, commodity spot prices and the S\&P 500 index at daily and 5-minute frequencies. At the daily frequency, we use the following data over the period 2000-2009: nominal exchange rates expressed as a number of domestic currency units per foreign currency (CAD/USD, CAD/GBP, AUD/USD, AUD/JPY, CLP/USD), effective exchange rates for the Canadian and Australian dollars, commodity spot prices in U.S. dollars (WTI crude oil, copper and gold), and the S\&P 500 index. The latter is an indicator of the general level of asset prices, which may have predictive power for both commodity prices and exchange rates. At the 5-minute frequency, we examine only the case of the Canadian dollar over the five-year period 2005-2009. Data descriptions, notation and sources are displayed in Table 1.

As already noted, we use the price of a single dominant exporting commodity for each country instead of the price of a country-specific commodity index. We focus on three typical pairs of commodity prices and exchange rates: Australian dollar and gold price, Canadian dollar and crude oil price and Chilean peso and copper price, because Granger-causality between these pairs of variables has attracted much attention both from academics and practitioners.

We first perform standard augmented Dickey-Fuller tests on the logarithms of all series and 
Table 1: Data description

\begin{tabular}{|c|c|c|}
\hline \multicolumn{3}{|c|}{ Daily Frequency: 2000 - 2009} \\
\hline Nominal Exchange Rates & Commodity Prices & Stock Index Price \\
\hline$A U D / U S D, A U D / J P Y, A U D(T W I)$ & Gold price & S\&P500 index price \\
\hline$C A D / U S D, C A D / G B P, C A D(C E R I)$ & WTI crude oil price & S\&P500 index price \\
\hline$C L P / U S D$ & Copper price & S\&P500 index price \\
\hline \multicolumn{3}{|c|}{ 5-minute Frequency: $2005-2009$} \\
\hline$C A D / U S D$ & WTI crude oil price & $S \& P 500$ index price \\
\hline
\end{tabular}

Data sources: daily CAD/USD and AUD/USD exchange rates are from the FRED data base at the Federal Reserve Bank of St. Louis [http://www.research.stlouisfed.org/fred2]; the daily CLP/USD exchange rate comes from Central Bank of Chile [http://www.bcentral.cl/eng/]; daily CAD/GBP and CERI are from Bank of Canada; daily AUD/JPY and Australia effective rate are from Bank of Australia; the daily WTI Crude oil price is from the Energy Information Administration [http://www.eia.doe.gov]; the daily gold price is from The London Bullion Market Association [http://www.lbma.org.uk]; the daily copper price comes from the Chilean Copper Commission [http://www.cochilco.cl/english/index.asp]; the daily S\&P500 composite index can be obtained from Yahoo Finance [http://finance.yahoo.com]; Intra-day (5-minute) data were obtained from the CQG data factory [http://www.cqg.com].

their first differences. The results (not reported) suggest that all variables in the level are nonstationary, and that the corresponding first differences are all stationary. Therefore, all data series are made stationary by taking the first difference following logarithmic transformations. We then model the transformed data series in each country as stationary and invertible VARMA processes with finite order. ${ }^{4}$ As discussed in Section 2, we use OLS to estimate a $\operatorname{VAR}(k)$ model to approximate the VARMA model (both unconstrained and constrained) which is autoregressive with potentially infinite order, where the value of $k$ is chosen according to the AIC. We first run Granger noncausality tests only at horizon one. We then estimate causality measures up to horizon 15 , based on (2.17) and build bootstrap confidence intervals.

\subsection{U.S. dollar-denominated exchange rates}

We now report and discuss the empirical results of Granger non-causality tests at horizon one, and multi-horizon causality measures for U.S. dollar-denominated exchange rates (i.e., exchange rates that use the U.S. dollar as numeraire, so that for example the CAD/US is the exchange rate measure taken for Canada).

The resulting $p$-values of unconditional and conditional Granger non-causality tests at horizon one for these exchange rates appear in Table 2. We present a large set of results in order to uncover broad patterns present in the data, and we summarize these patterns in the text. The results of these horizon-one tests can be characterized as follows. In both unconditional and conditional tests, the non-causality hypothesis is in general rejected in both directions between commodity prices and

\footnotetext{
${ }^{4}$ In unconditional cases, the model involves only two variables: exchange rate and commodity price. In conditional cases, the model involves three variables: exchange rate, commodity price and S\&P500 price.
} 
exchange rates at daily and 5-minute frequencies. Non-causality tests from the S\&P 500 index to exchange rates are strongly significant in all cases, but we cannot reject the non-causality hypothesis in the reverse direction for Canadian and Chilean cases at the daily frequency. Causality between the S\&P 500 index and the crude oil price at the daily frequency exists in both directions. The price of gold is found to Granger-cause the S\&P 500 index but not vice versa, and causality is found from the S\&P 500 index to the price of copper, but not in the other direction.

As expected, the general level of asset prices (as captured by the S\&P 500) has predictive power for both exchange rates and commodity prices. It is therefore a potential vehicle for examining indirect causality. In the 5-minute Canadian data, we fail to reject non-causality from the crude oil price to the S\&P 500 price, but non-causality from the exchange rate to the S\&P 500 price is rejected. Contrasting with the daily-data results underscores the fact that different causality patterns can be obtained by using data at different frequencies, since changing the data frequency implies changing the information set used for prediction.

We find evidence of some degree of causal impact in all directions. Of course, this apparent symmetry may mask substantial differences in the strengths of these effects; in some cases, causality may be very weak even if non-causality is rejected. We now turn to measures of the magnitudes of these effects. To compare the causal relationships, we compute the causality measures based on the methods described in Section 2. The results are reported primarily through graphics.

The unconditional causality measures are reported in Figures 1 and 2, and the conditional causality measures are reported in Figures $3-8$, in each case up to a fifteen periods horizon. A causality measure is statistically significant when the confidence interval does not include the value zero; for example, from the top left panel of Figure 1, we can conclude that crude oil has significant predictive power for the CAD/USD exchange rate up to 3 days. In reading the figures, note that vertical scales may differ; to facilitate comparisons we have therefore included a number of panels in which effects in the two directions are recorded on a common scale.

We note a few broad patterns that are observable in the figures: (1) causality measures usually have the highest value at horizon one and decrease with increasing prediction horizon, and tend to converge toward zero with increasingly tight confidence intervals; (2) in cases where the noncausality hypothesis is not rejected, we typically find the corresponding measures are low but still statistically significant, which may indicate that causality measures provide a more powerful way to test Granger non-causality; in cases where non-causality is rejected in both directions, causality measures in the two directions can typically be distinguished to some extent.

To streamline the following explanations, we will use the following short forms: to express the relationship that causality from $A$ to $B$ is stronger (weaker) than causality from $B$ to $A$ at horizon $h$, we simply say that 'causality from $A$ to $B$ is stronger (weaker) at horizon $h$ '. When we say, without a specific horizon, that 'multi-horizon causality from $A$ to $B$ is stronger (weaker)' this indicates that causality from $A$ to $B$ is stronger (weaker) than causality from $B$ to $A$, up to the horizon at which both measures decrease to values very close to zero.

Figures 1 and 2 treat unconditional cases in which the top four panels represent causality measures with confidence intervals, and the bottom two panels are comparisons of two directions of causality. Figures 3 and 4 are conditional causality measures with confidence intervals, for Canadian data at the daily and 5-minute frequencies respectively. Figure 5 is a comparison of two directions 
Table 2: Granger non-causality tests - CAD/USD, AUS/USD, CLP/USD

(Daily: 4/1/2000 - 30/12/2009, 5-minute: 3/1/2005 - 31/12/2009)

\begin{tabular}{ccccccc}
\hline \hline & & & & & & \\
& Panel A: Unconditional non-causality tests [ bivariate model $(P$, ex $)$ ] & \\
\hline Canada & Daily & 5 minutes & Australia & Daily & Chile & Daily \\
\hline$P_{\text {oil }} \nrightarrow C A D / U S D$ & 0.007 & 0.000 & $P_{\text {gold }} \nrightarrow A U D / U S D$ & 0.000 & $P_{\text {copper }} \nrightarrow C L P / U S D$ & 0.000 \\
\hline$C A D / U S D \nrightarrow P_{\text {oil }}$ & 0.057 & 0.000 & $A U D / U S D \nrightarrow P_{\text {gold }}$ & 0.000 & $C L P / U S D \nrightarrow P_{\text {copper }}$ & 0.001 \\
\hline
\end{tabular}

Panel B: Conditional non-causality tests [ trivariate model $(P, e x, S P)$ ]

\begin{tabular}{lllllll}
\hline$P_{\text {oil }} \nrightarrow C A D / U S D$ & 0.028 & 0.000 & $P_{\text {gold }} \nrightarrow A U D / U S D$ & 0.000 & $P_{\text {copper }} \nrightarrow C L P / U S D$ & 0.000 \\
\hline$C A D / U S D \nrightarrow P_{\text {oil }}$ & 0.030 & 0.002 & $A U D / U S D \nrightarrow P_{\text {gold }}$ & 0.000 & $C L P / U S D \nrightarrow P_{\text {copper }}$ & 0.001 \\
\hline$S P \nrightarrow C A D / U S D$ & 0.000 & 0.000 & $S P \nrightarrow A U D / U S D$ & 0.000 & $S P \nrightarrow C L P / U S D$ & 0.000 \\
\hline$C A D / U S D \nrightarrow S P$ & 0.489 & 0.000 & $A U D / U S D \nrightarrow S P$ & 0.000 & $C L P / U S D \nrightarrow S P$ & 0.179 \\
\hline$S P \nrightarrow P_{\text {oil }}$ & 0.004 & 0.000 & $S P \nrightarrow P_{\text {gold }}$ & 0.086 & $S P \nrightarrow P_{\text {copper }}$ & 0.000 \\
\hline$P_{\text {oil }} \nrightarrow S P$ & 0.044 & 0.722 & $P_{\text {gold }} \nrightarrow S P$ & 0.010 & $P_{\text {copper }} \nrightarrow S P$ & 0.399 \\
\hline \hline
\end{tabular}

The notations $P$ and $S P$ represent the price of commodity and the price of S\&P500 index respectively. 
in the pairs of causality relationships included in Figures 3 and 4. Figures 6 and 7 are conditional causality measures with confidence intervals for the Australian and Chilean data respectively, and Figure 8 is a comparison of two directions in the causality relationships included in Figures 6 and 7.

We can summarize the results implied in Figures $1-8$ as follows.

1. At the daily frequency, the bottom left panel of Figure 1 indicates that causality from the crude oil price to the CAD/USD exchange rate is stronger at horizon one, but beyond horizon one, estimated causality in the reverse direction becomes stronger. Including the S\&P 500 index slightly weakens causality from the crude oil price to the CAD/USD exchange rate at horizon one (the ratio is near 1.35 in favour of the commodity to exchange rate link), as shown in the top left panel of Figure 5, but otherwise changes little. At the 5-minute frequency, causality from the crude oil price to CAD/USD is much stronger at horizon one (the ratio exceeds 3.0 in favour of the commodity to exchange rate link), beyond which causality in both directions becomes very weak (see the bottom right panel of Figure 1). The fourth panel of Figure 5 shows that conditional results display causality patterns similar to those in unconditional results.

2. For daily Australian data, causality from the AUD/USD to the gold price is stronger at horizon one (almost twice as high according to our causality measure), beyond which the dominant direction of causality alternates (see the bottom left panel of Figure 2). In comparison, the top left panel of Figure 8 shows that including the S\&P 500 index helps to identify causality from the gold price to the AUD/USD exchange rate.

3. For daily Chilean data, multi-horizon causality from the copper price to the CLP/USD exchange rate is much stronger (by a factor of 10), and conditional results display similar causality patterns (see the bottom right panel of Figure 2 and the right-middle panel of Figure $8)$.

4. From Figures 5 and 8, multi-horizon causality from the S\&P 500 to exchange rates is generally found to be stronger both at daily and 5-minute frequencies; multi-horizon causality from the gold price to the $S \& P 500$ is stronger, while multi-horizon causality from the copper price to the S\&P 500 is weaker; multi-horizon causality from the crude oil price to the S\&P 500 is weaker for 5-minute data and stronger from horizon two for daily data.

Globally, these results suggest stronger causation from commodity to currency rather than vice versa, but the results are by no means unambiguous. We now consider whether eliminating dollar effects can clarify the overall pattern.

\subsection{Non-U.S. dollar-denominated exchange rates}

The exchange rates and commodity prices used above are denominated in US dollars, so our results may be affected by this choice. For example, the sizable causality measures noted above from $\mathrm{CAD} / \mathrm{USD}$ to the crude oil price and from AUD/USD to the gold price may be partially due to such a U.S. dollar denomination effect or dollar effect. To avoid attributing causal effects to this source, 
Table 3: Granger non-causality tests - CAD/GBP, CAD $(C E R I)$

(Daily: 4/1/2000 - 30/12/2009)

\begin{tabular}{|c|c|c|c|}
\hline \multicolumn{4}{|c|}{ Panel A: Unconditional non-causality tests [ bivariate model $(P, e x)$ ] } \\
\hline$P_{\text {oil }} \nrightarrow C A D / G B P$ & 0.026 & $P_{\text {oil }} \nrightarrow C A D(C E R I)$ & 0.005 \\
\hline$C A D / G B P \nrightarrow P_{\text {oil }}$ & 0.174 & $C E R I \nrightarrow P_{o i l}$ & 0.337 \\
\hline \multicolumn{4}{|c|}{ Panel B: Conditional non-causality tests [ trivariate model $(P, e x, S P)]$} \\
\hline$P_{\text {oil }} \nrightarrow C A D / G B P$ & 0.091 & $P_{\text {oil }} \nrightarrow C A D(C E R I)$ & 0.008 \\
\hline$C A D / G B P \nrightarrow P_{o i l}$ & 0.159 & $C A D(C E R I) \nrightarrow P_{o i l}$ & 0.195 \\
\hline$S P \nrightarrow C A D / G B P$ & 0.000 & $S P \nrightarrow C A D(C E R I)$ & 0.000 \\
\hline$C A D / G B P \nrightarrow S P$ & 0.255 & $C A D(C E R I) \nrightarrow S P$ & 0.162 \\
\hline$S P \nrightarrow P_{o i l}$ & 0.033 & $S P \nrightarrow P_{\text {oil }}$ & 0.027 \\
\hline$P_{o i l} \nrightarrow S P$ & 0.027 & $P_{\text {oil }} \nrightarrow S P$ & 0.016 \\
\hline
\end{tabular}

we repeat the above analysis using alternative currency benchmarks: for Canada the CAD/GBP and the Canadian effective rate (CERI); for Australia AUD/JPY and the Australian effective rate (TWI). The corresponding results for non-causality tests and causality measures are displayed in Tables 3 - 4 and Figures 9-16. Once again, we present numerous results in order to help discern typical patterns. From these results, we find that eliminating the dollar effects leads to detection of a clearer causal direction from commodity prices to exchange rates across all horizons, both in conditional and conditional analyses.

Consider first non-causality tests at horizon one: in Table 2, causality between exchange rates with the US dollar numeraire and commodity prices is generally bi-directional, whereas $p$-values in the non-dollar-denominated cases of Tables 3 and 4 imply a clear causal direction from commodity prices to exchange rates.

Next we examine the multi-horizon measures displayed in Figures 9-16. Figures 9 and 10 report unconditional analyses in which the top four panels represent causality measures with confidence intervals, and the bottom two panels are comparisons of two directions in a pair of causality relationships. Figures 11 and 12 depict conditional causality measures with confidence intervals for the CAD/GBP and Canadian effective rate (CERI) exchange rates respectively. Figure 13 is a comparison of the two directions of causality included in Figures 11 and 12. Figures 14 and are conditional causality measures with confidence intervals for the AUD/JPY and Australian TWI exchange rates respectively. Figure 16 is the comparison of the directions of causality for the cases included in Figures 14 and 15. We stress the following observations.

1. In contrast with the bottom left panel of Figure 1 (where causality from the crude oil price to the CAD/USD is stronger at horizon one by factors up to 3, but beyond horizon one causality in the reverse direction becomes stronger), the analogous results in the bottom panels of 
Table 4: Granger non-causality tests - AUD/JPY, AUD $(T W I)$

(Daily: 4/1/2000 - 30/12/2009)

\begin{tabular}{|c|c|c|c|}
\hline \multicolumn{4}{|c|}{ Panel A: Unconditional non-causality tests [ bivariate model $(P, e x)$ ] } \\
\hline$P_{\text {gold }} \nrightarrow A U D / J P Y$ & 0.008 & $P_{\text {gold }} \nrightarrow A U D(T W I)$ & 0.000 \\
\hline$A U D / J P Y \nrightarrow P_{\text {gold }}$ & 0.785 & $A U D(T W I) \nrightarrow P_{\text {gold }}$ & 0.440 \\
\hline \multicolumn{4}{|c|}{ Panel B: Conditional non-causality tests [ trivariate model $(P, e x, S P)]$} \\
\hline$P_{\text {gold }} \nrightarrow A U D / J P Y$ & 0.000 & $P_{\text {gold }} \nrightarrow A U D(T W I)$ & 0.000 \\
\hline$A U D / J P Y \nrightarrow P_{\text {gold }}$ & 0.755 & $A U D(T W I) \nrightarrow P_{\text {gold }}$ & 0.607 \\
\hline$S P \nrightarrow A U D / J P Y$ & 0.000 & $S P \nrightarrow A U D(T W I)$ & 0.000 \\
\hline$A U D / J P Y \nrightarrow S P$ & 0.053 & $A U D(T W I) \nrightarrow S P$ & 0.158 \\
\hline$S P \nrightarrow P_{\text {gold }}$ & 0.033 & $S P \nrightarrow P_{\text {gold }}$ & 0.000 \\
\hline$P_{\text {gold }} \nrightarrow S P$ & 0.413 & $P_{\text {gold }} \nrightarrow S P$ & 0.349 \\
\hline
\end{tabular}

Figure 9 show that multi-horizon causality from the crude oil price to the CAD/GBP and CERI is much stronger. Conditional results show a similar causality pattern.

2. Compared with the bottom left panel of Figure 6 (in which the dominant direction of causality alternates across 15 horizons), the bottom panels of Figure 10 illustrate that multi-horizon causality from the gold price to the AUD/JPY and Australian TWI is much stronger. Conditional results again show a similar causality pattern. In addition, from Figures 13 and 16, we observe that causality from the S\&P 500 to all four exchange rates that we consider here is much stronger, especially at horizon one; multi-horizon causality from the oil price to the S\&P 500 is stronger, but causality from the gold price to the S\&P 500 is weaker at horizon one.

In general, eliminating dollar effects leads to a clearer pattern of multi-horizon causality direction running from commodity prices to exchange rates at the daily frequency. The results are robust to consideration of conditional causality patterns using the S\&P 500 as an auxiliary variable.

\section{Conclusion}

Both popular commentary and economic reasoning based on demand for currencies in small open economies suggest that causality should run from commodity prices to exchange rates, but the present value model of forward-looking exchange rates implies that exchange rates should Grangercause commodity prices. The debate on the direction of causality between commodity prices and exchange rates is still open. In order to investigate this topic further, we have examined high-frequency causal relationships between exchange rates of three typical commodity economies (Canada, Aus- 
tralia, and Chile) and the prices of their corresponding dominant exporting commodities (crude oil, gold, and copper). We use daily and 5-minute data, which is of great interest to financial market participants who have short decision intervals, and also reduces time-aggregation effects. In addition, we have applied the concept of multi-horizon causality measures to compare the strength of causal relationships, to provide more powerful non-causality tests, and to determine how long the causal effects will last.

In contrast with previous studies, our results suggest unconditional and conditional causality running from commodity prices to exchange rates is stronger than that in the opposite direction across multiple horizons, after removing potential dollar effects. These results suggest that the macroeconomic/trade-based mechanism mentioned in the introduction plays a central role in exchange rate dynamics, despite the financial features of these markets. To "see" these effects in the data, it is however important to consider a sufficiently high data frequency and to use an appropriate causal methodology. The results also underscore the facts that the interpretation of causality depends on time units and observation intervals (data frequency), and that causality measures present a more informative analysis of Granger causality than tests of non-causality alone.

High-frequency data are potentially very fruitful in causality studies, allowing us to distinguish with high resolution between immediate and lagged effects corresponding with different agents' interests. However, there remain further avenues to investigate. For example, in our causality measures with 5-minute data, we estimate the VAR model at this frequency and the causality measures lasting up to 13 periods, that is, only about one hour. If we were to allow longer periods for the effects to develop we would need a large number of lags in the VAR model, sacrificing estimation efficiency. One possible method of handling this difficulty is to use mixed-data sampling (MIDAS) and mixed-frequency VAR (MF- VAR) approaches [Ghysels, Santa-Clara and Valkanov (2004), Ghysels, Sinko and Valkanov (2007), Ghysels, Hill and Motegi (2013) and Kuzin, Marcellino and Schumacher (2010)]. Furthermore, it is interesting to consider out-of-sample tests for Granger causality [Inoue and Kilian (2004) and Chen (2005)]. Another worthwhile extension would be to examine second-order causality between commodity prices and exchange rates [Granger, Robins and Engle (1986), Comte and Lieberman (2000), Hafner (2009), and Dufour and Zhang (2012)]. 


\section{References}

Alquist, R., Kilian, L. and Vigfusson, R. J. (2012), Forecasting the price of oil, in G. Elliott and A. Timmermann, eds, 'Handbook of Economic Forecasting', first edn, Vol. 2A, Elsevier, Amsterdam.

Amano, R. and van Norden, S. (1995), 'Terms of trade and real exchange rates: The canadian evidence', Journal of International Money and Finance 14, 83-104.

Amano, R. and van Norden, S. (1998a), 'Exchange rates and oil prices', Review of International Economics 6, 683-694.

Amano, R. and van Norden, S. (1998b), 'Oil prices and the rise and fall of the U.S. real exchange rate', Journal of International Money and Finance 17, 299-316.

Baillie, R. T. and McMahon, P. C. (1989), The Foreign Exchange Market: Theory and Econometric Evidence, Cambridge University Press, Cambridge, UK.

Bernard, J.-T., Dufour, J.-M., Khalaf, L. and Kichian, M. (2012), 'An identification-robust test for time-varying parameters in the dynamics of energy prices', Journal of Applied Econometrics 27, 603-624.

Breitung, J. and Swanson, N. R. (2002), 'Temporal aggregation and causality in multiple time series models', Journal of Time Series Analysis 23, 651-665.

Cashina, P., Ceśpedesb, L. F. and Sahay, R. (2004), 'Commodity currencies and the real exchange rate', Journal of Development Economics 75, 239-268.

Chen, S.-S. (2005), 'A note on in-sample and out-of-sample tests for Granger causality', Journal of Forecasting 24, 453-464.

Chen, Y.-C. (2004), Exchange rates and fundamentals: Evidence from commodity currencies, Technical report, Department of Economics, University of Washington.

Chen, Y.-C. and Rogoff, K. (2003), 'Commodity currencies', Journal of International Economics 60, 133-160.

Chen, Y.-C., Rogoff, K. and Rossi, B. (2010), 'Can exchange rates forecast commodity prices?', Quarterly Journal of Economics 125, 1145-1194.

Cheung, Y.-W., Chinn, M. D. and Pascual, A. G. (2005), 'Empirical exchange rate models of the nineties: Are any fit to survive?', Journal of International Money and Finance 24, 1150-1175.

Comte, F. and Lieberman, O. (2000), 'Second-order noncausality in multivariate garch processes', Journal of Time Series Analysis 21(5), 535-557. 
Dufour, J.-M., Garcia, R. and Taamouti, A. (2012), 'Measuring high-frequency causality between returns, realized volatility, and implied volatility', Journal of Financial Econometrics 10(1), 124-163.

Dufour, J.-M., Pelletier, D. and Renault, E. (2006), 'Short-run and long-run causality in time series: Inference', Journal of Econometrics 132(2), 337-362.

Dufour, J.-M. and Renault, E. (1998), 'Short-run and long-run causality in time series: Theory', Econometrica 66(5), 1099-1125.

Dufour, J.-M. and Taamouti, A. (2010), 'Short and long run causality measures: Theory and inference', Journal of Econometrics 154, 42-58.

Dufour, J.-M. and Zhang, H. J. (2012), Short and long run second-order causality: Theory, measures and inference, Technical report, Department of Economics, McGill University.

Engel, C. and West, K. D. (2005), 'Exchange rates and fundamentals', Journal of Political Economy 113, 485-517.

Ferraro, D., Rogoff, K. and Rossi, B. (2012), Can oil prices forecast exchange rates?, Technical report, Duke University.

Frankel, J. A. and Rose, A. K. (1995), Empirical resarch on nominal exchange rates, in (Grossman and Rogoff 1995), chapter 33, pp. 1689-1729.

Froot, K. A. and Rogoff, K. (1995), Perspectives on PPP and long-run real exchange rates, in (Grossman and Rogoff 1995), chapter 32, pp. 1647-1688.

Geweke, J. (1982), 'Measurement of linear dependence and feedback between multiple time series', Journal of the American Statistical Association 77, 304-313.

Geweke, J. (1984), 'Measures of conditional linear dependence and feedback between time series', Journal of the American Statistical Association 79, 907-915.

Ghysels, E., Hill, J. B. and Motegi, K. (2013), Granger causality in mixed frequency vector autoregressive models, Technical report, Department of Economics, University of North Carolina, Chapel-Hill, North Carolina.

Ghysels, E., Santa-Clara, P. and Valkanov, R. (2004), The midas touch: Mixed data sampling regression, Technical report, Department of Economics, University of North Carolina, Chapel-Hill, North Carolina.

Ghysels, E., Sinko, A. and Valkanov, R. I. (2007), 'MIDAS regressions: Further results and new directions', Econometric Reviews 26, 53-90.

Granger, C. W. J. (1969), 'Investigating causal relations by econometric models and cross-spectral methods', Econometrica 37, 424-459. 
Granger, C. W. J., Robins, R. and Engle, R. F. (1986), Wholesale and retail prices: Bivariate time series modeling with forecastable error variances, in D. A. Belsey and E. Kuh, eds, 'Model Reliability', MIT Press, Boston, MA.

Grossman, G. M. and Rogoff, K., eds (1995), Handbook of International Economics, Volume III, Elsevier, Amsterdam.

Gruen, D. W. and Wilkinson, J. (1994), 'Australia's real exchange rate - is it explained by the terms of trade or by real interest rate differentials?', Economic Record 70, 204-219.

Hafner, C. M. (2009), 'Causality and forecasting in temporally aggregated multivariate garch processes', Econometrics Journal 12, 127-146.

Hamilton, J. D. (2009), 'Understanding crude oil prices', Energy Journal 30, 179-206.

Hamilton, J. D. and Herrera, A. M. (2004), 'Oil shocks and aggregate macroeconomic behavior: the role of monetary policy', Journal of Money Credit and Banking 36, 265-286.

Inoue, A. and Kilian, L. (2004), 'In-sample or out-of-sample tests of predictability: which one should we use?', Econometric Reviews 23(4), 371-402.

Isard, P. (1995), Exchange Rate Economics, Cambridge Surveys of Economic Literature, Cambridge University Press, Cambridge, U.K.

Issa, R., Lafrance, R. and Murray, J. (2008), 'The turning black tide: Energy prices and the Canadian dollar', Canadian Journal of Economics 41, 737-759.

Kilian, L. (2008), 'The economic effects of energy price shocks', Journal of Economic Literature 46, 871-909.

Kilian, L. (2009), 'Not all oil price shocks are alike: disentangling demand and supply shocks in the crude oil market', American Economic Review 99, 1053-1069.

Kilian, L. and Park, C. (2009), 'The impact of oil price shocks on the U.S. stock market', International Economic Review 50, 1267-1287.

Kilian, L. and Taylor, M. P. (2003), 'Why is it so difficult to beat the random walk forecast of exchange rates?', Journal of International Economics 60(1), 85-107.

Kuzin, V., Marcellino, M. and Schumacher, C. (2010), 'MIDAS vs mixed-frequency VAR for nowcasting GDP in the Euro area', International Journal of Forecasting 27, 529-542.

Levich, R. M. (1985), Empirical studies of exchange rates: Price behavior, rate determination and market efficiency, in R. W. Jones and P. B. Kenen, eds, 'Handbook of International Economics, Volume II, International Monetary Economics and Finance', North-Holland, Amsterdam, chapter 19, pp. 979-1040. 
Lewis, R. and Reinsel, G. C. (1985), 'Prediction of multivariate time series by autoregressive model fitting', Journal of Multivariate Analysis 16, 392-411.

Lütkepohl, H. (1993), Introduction to Multiple Time Series Analysis, second edn, Springer-Verlag, Berlin.

Marcellino, M. (1999), 'Some consequences of temporal aggregation in empirical analysis', Journal of Business and Economic Statistics 17, 129-136.

Mark, N. (2001), International Macroeconomics and Finance: Theory and Econometric Methods, Blackwell, Oxford, UK.

Meese, R. and Rogoff, K. (1983), 'Exchange rate models of the seventies: Do they fit out of sample?', Journal of International Economics 14, 3-24.

Obstfeld, M. and Rogoff, K. S. (1996), Foundations of International Macroeconomics, MIT Press, Cambridge, MA.

Pindyck, R. S. (2001), 'The dynamics of commodity spot and futures markets: a primer', Energy Journal 22, 1-29.

Rogoff, K. and Stavrakeva, V. (2008), 'The continuing puzzle of short horizon exchange rate forecasting', NBER Working Paper 14071.

Rossi, B. (2013), 'Exchange rate predictability', Journal of Economic Literature forthcoming.

Sarno, L. and Taylor, M. P. (2002), The Economics of Exchange Rates, Cambridge University Press, Cambridge, U.K.

Schwartz, E. S. (1997), 'The stochastic behavior of commodity prices: implications for valuation and hedging', Journal of Finance 52, 923-973.

Schwartz, E. S. and Smith, J. E. (2000), 'Short-term variations and long-term dynamics in commodity prices', Management Science 46, 893-911.

Silvestrini, A. and Veredas, D. (2008), 'Temporal aggregation of univariate and multivariate time series models: A survey', Journal of Economic Surveys 22, 458-497.

Tabak, B. M. and Cajueiro, D. O. (2007), 'Are the crude oil markets becoming weakly efficient over time? A test for time-varying long-range dependence in prices and volatility', Energy Economics 29, 28-36.

Tiao, G. C. and Wei, W. W. S. (1976), 'Effect of temporal aggregation on the dynamic relationship of two time series variables', Biometrika 63, 513-523.

Wei, W. W. S. (1982), 'The effect of systematic sampling and temporal aggregation on causality - a cautionary note', Journal of the American Statistical Association 77, 316-319. 
Wei, W. W. S. (1990), Time Series Analysis: Univariate and Multi Variate Methods, AddisonWesley, California. 

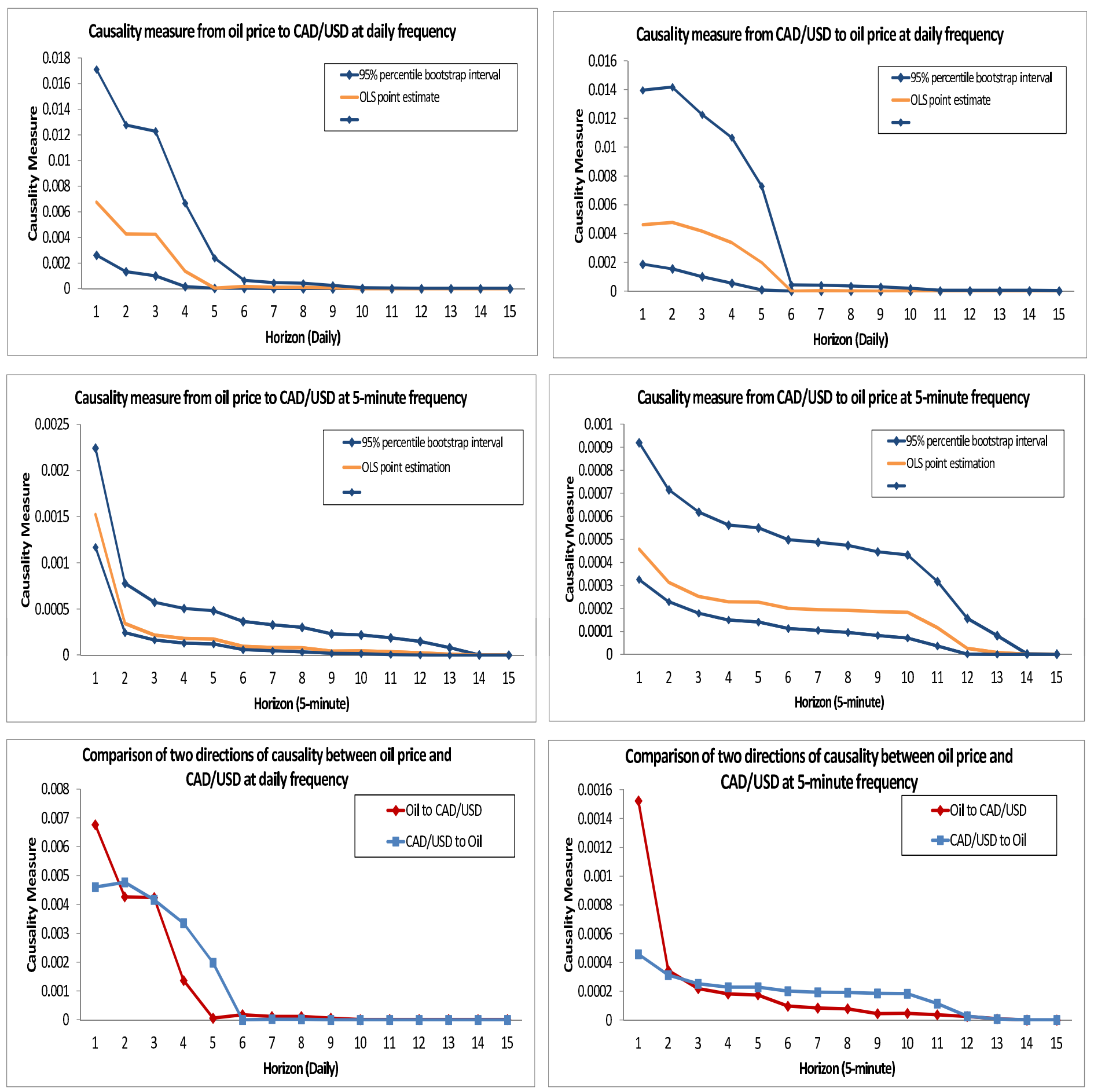

Figure 1. Unconditional causality measures between CAD/USD and oil price

(Daily: 4/1/2000 - 30/12/2009, 5-minute: 3/1/2005 - 31/12/2009) 

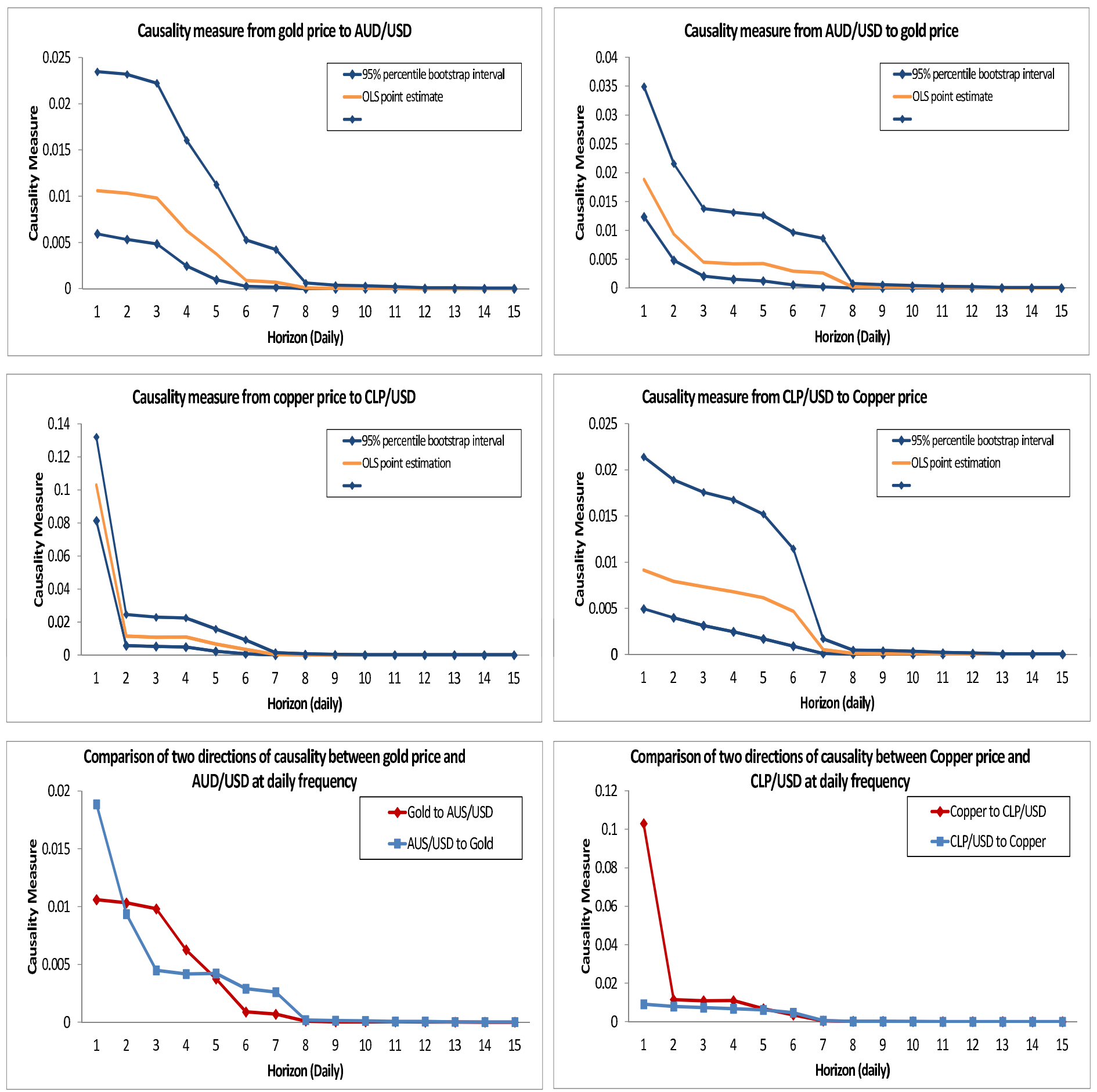

Figure 2. Unconditional causality measures between AUD/USD and gold price; between

CLP/USD and copper price (Daily: 4/1/2000 - 30/12/2009) 

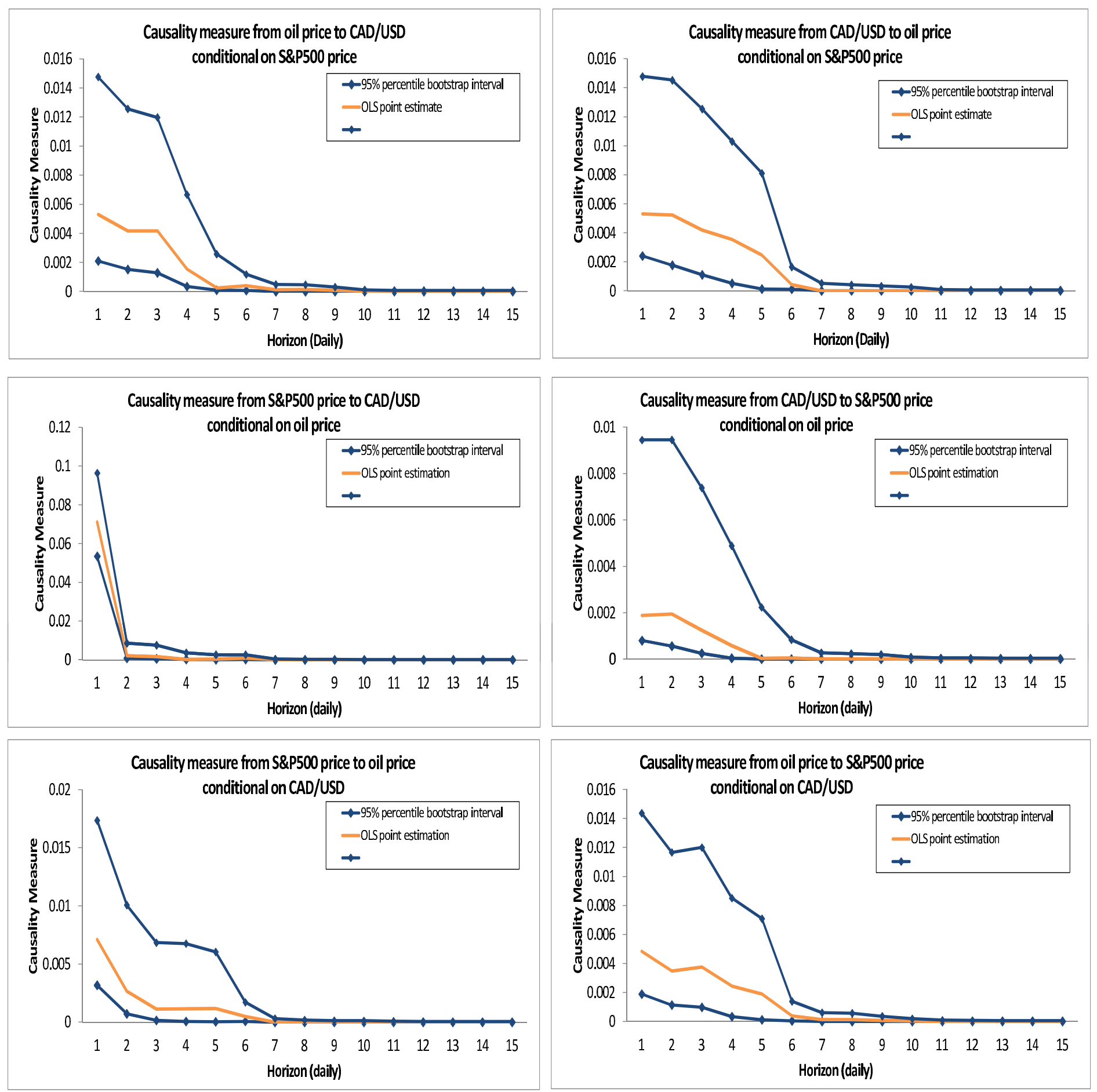

Figure 3. Conditional causality measures between CAD/USD, oil price and S\&P500 price (Daily: 4/1/2000 - 30/12/2009) 

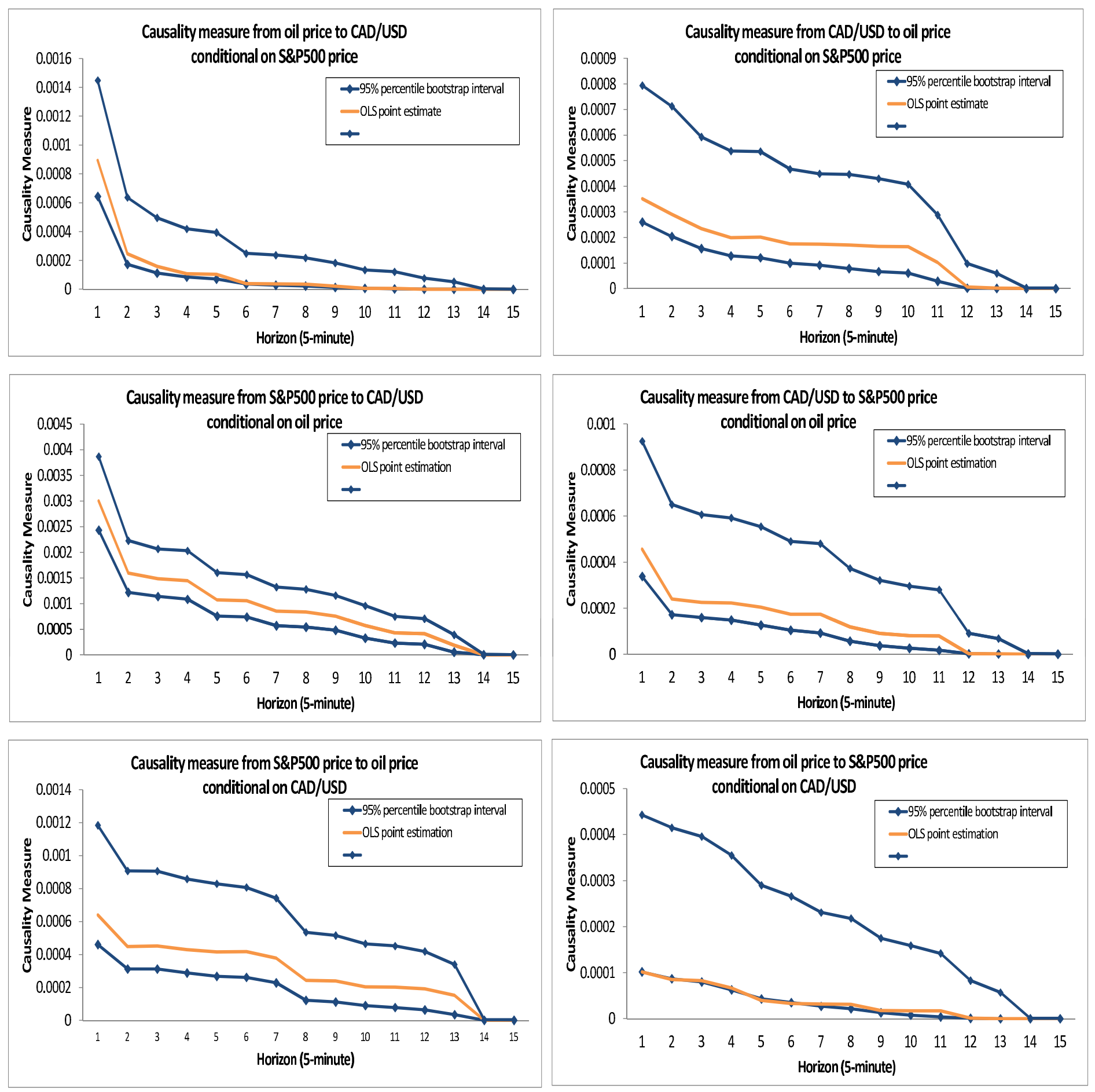

Figure 4. Conditional causality measures between CAD/USD, oil price and S\&P500 price

(5-minute: 3/1/2005 - 31/12/2009) 

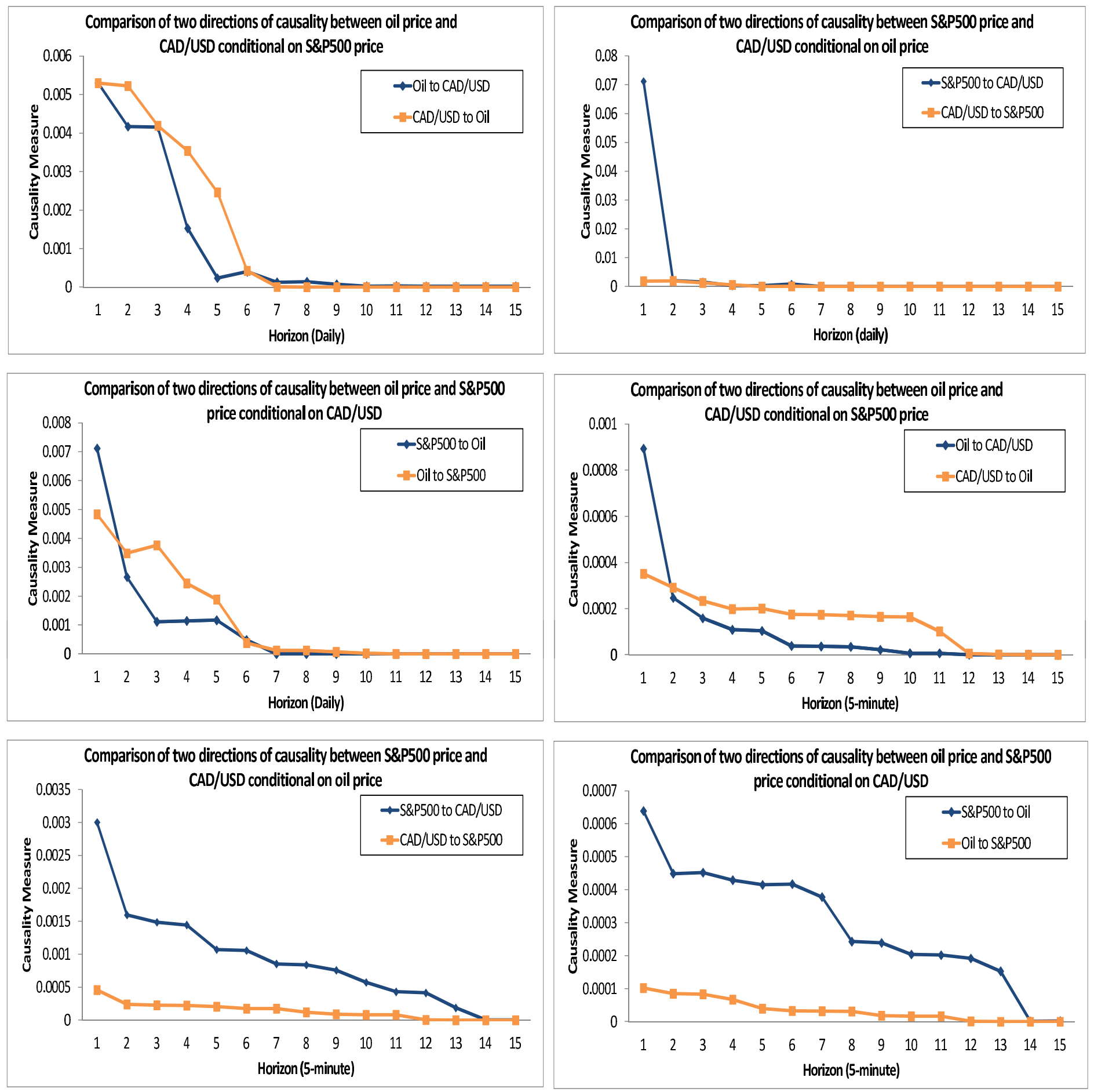

Figure 5. Comparison of two directions of causality between CAD/USD, oil price and S\&P500 price

(Daily: 4/1/2000 - 30/12/2009, 5-minute: 3/1/2005 - 31/12/2009) 

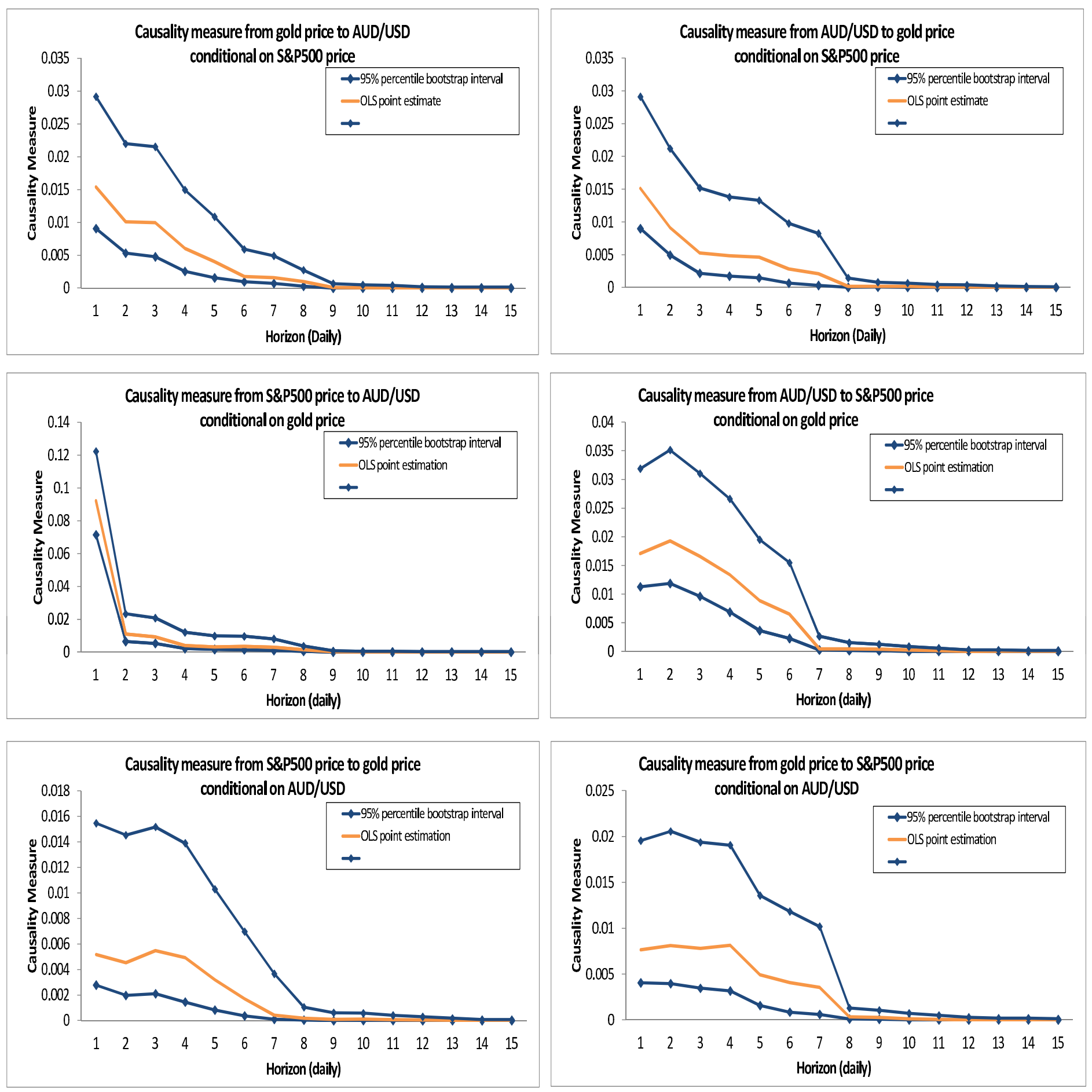

Figure 6. Conditional causality measures between AUD/USD, gold price and S\&P500 price

(Daily: 4/1/2000 - 30/12/2009) 

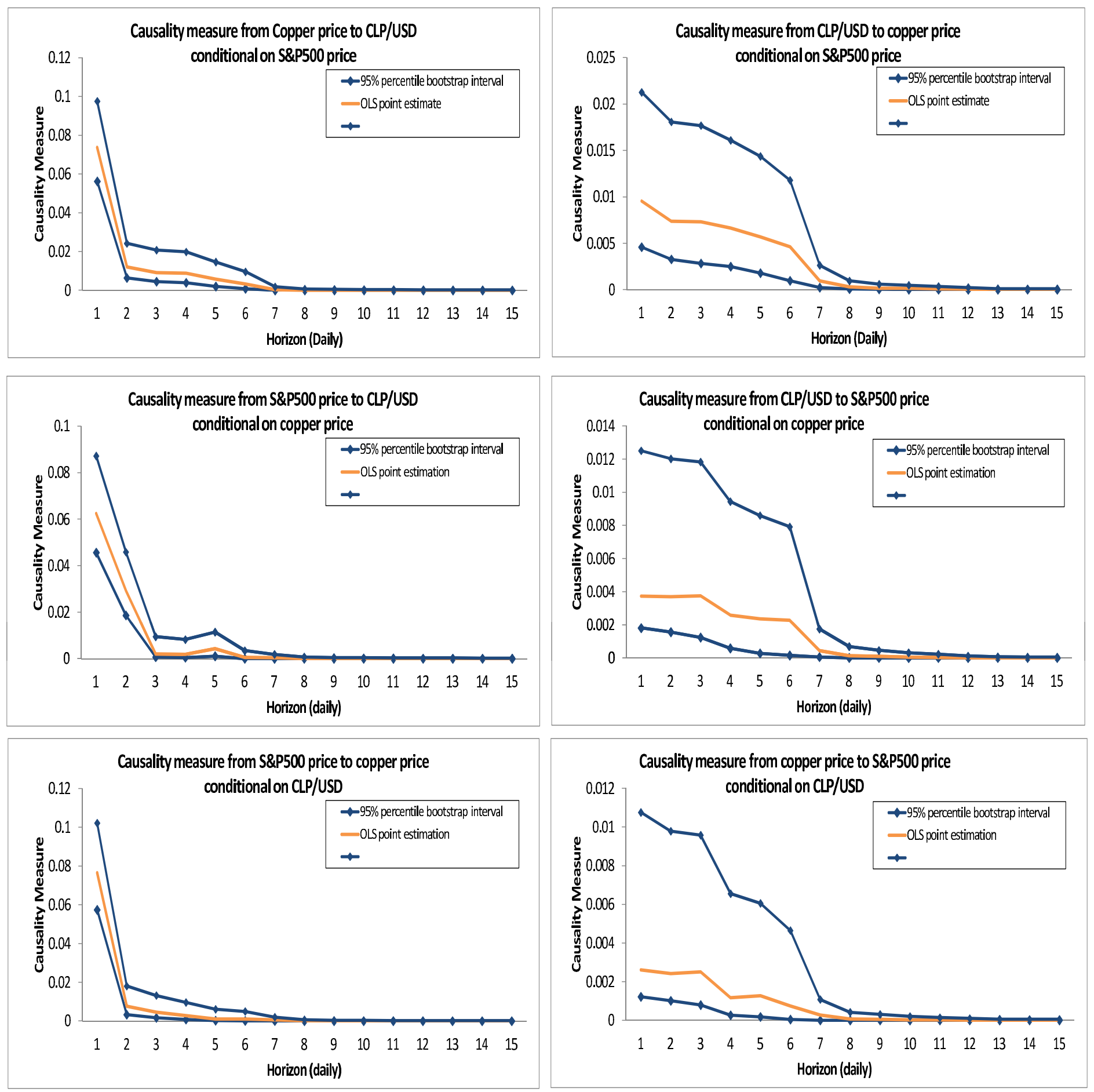

Figure 7. Conditional causality measures between CLP/USD, copper price and S\&P500 price

(Daily: 4/1/2000 - 30/12/2009) 

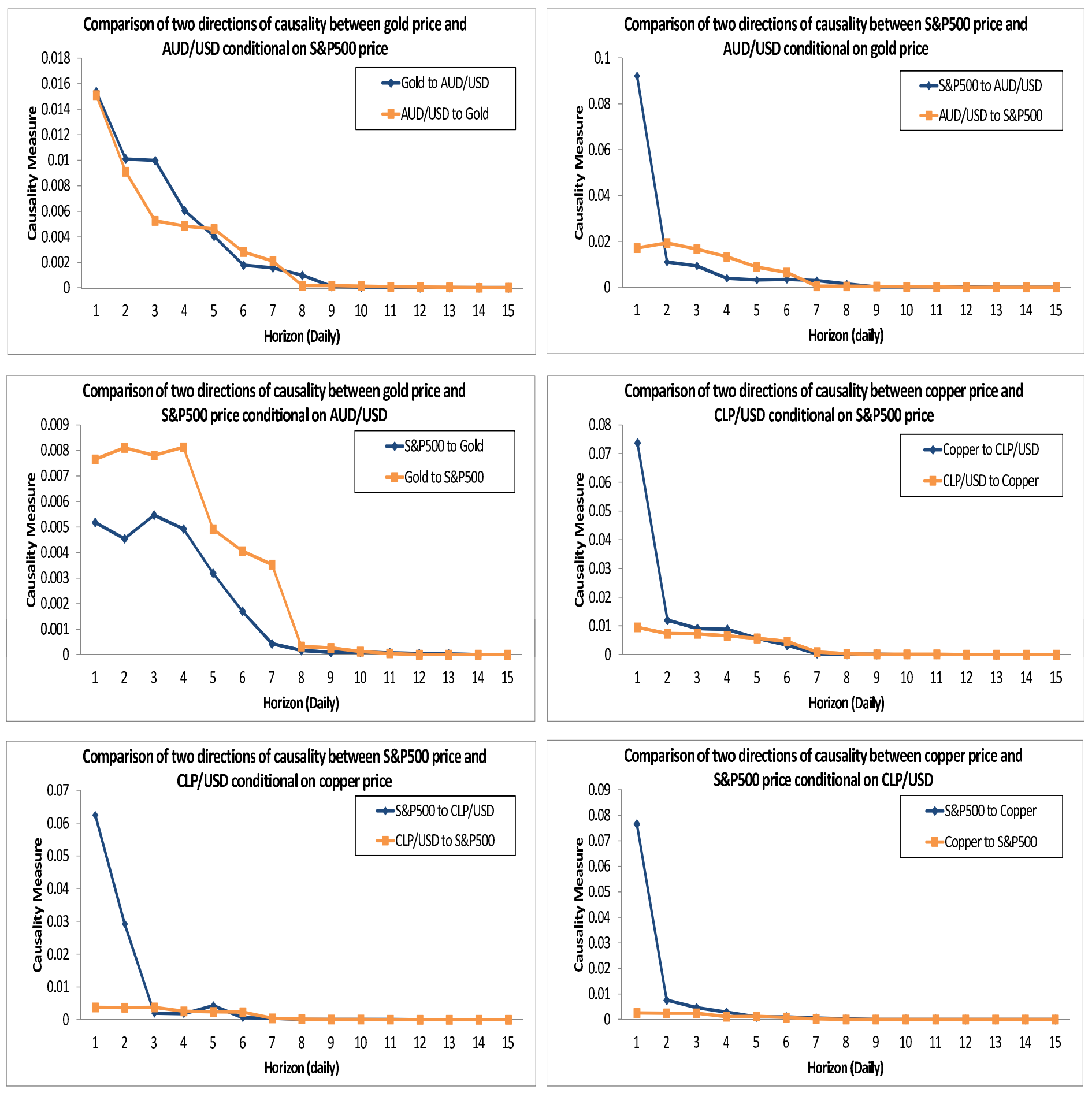

Figure 8. Comparison of two directions of causality between AUD/USD, gold price and S\&P500 price; between CLP/USD, copper price and S\&P500 price (Daily: 4/1/2000 - 30/12/2009) 

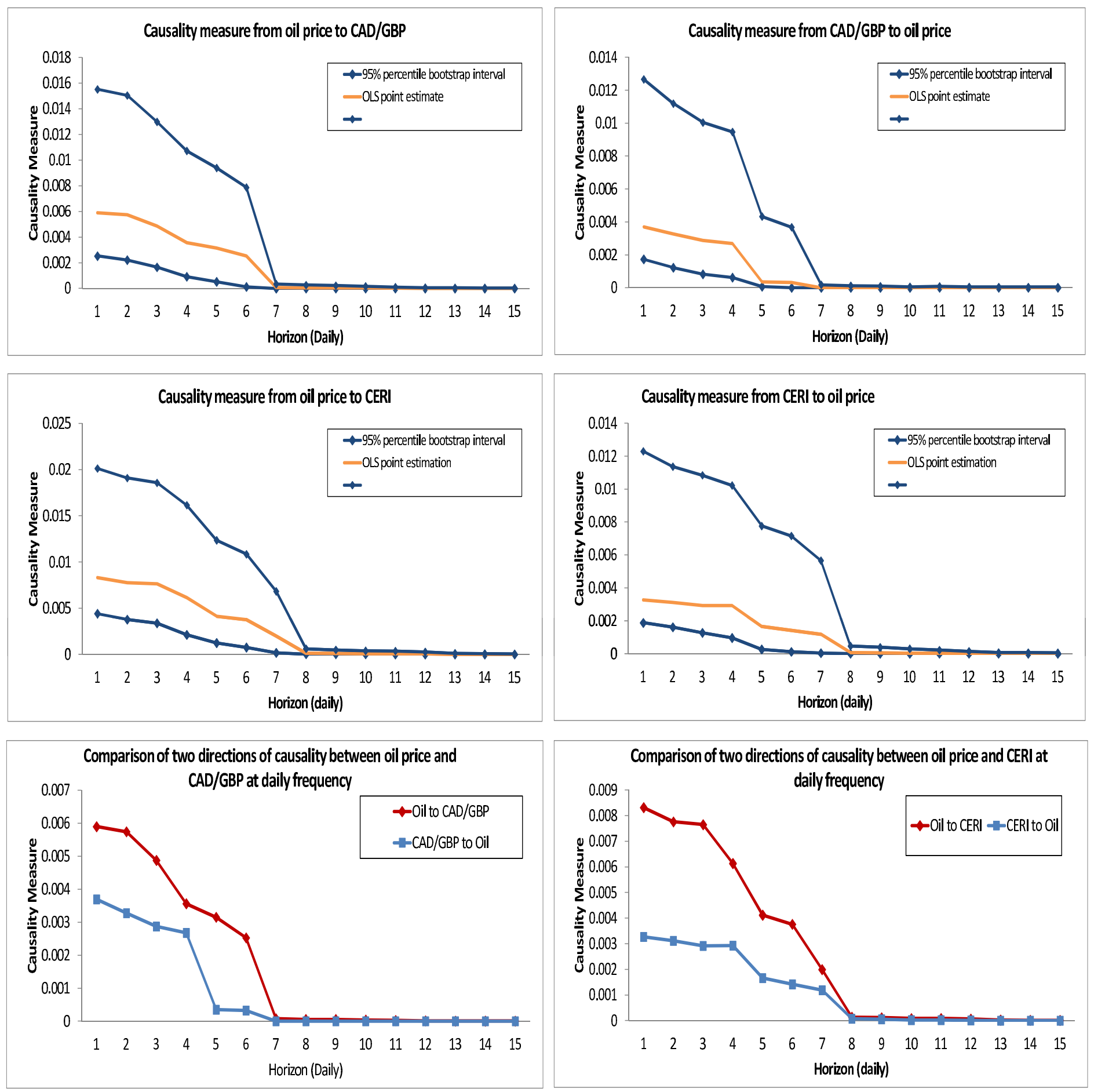

Figure 9. Unconditional causality measures between CAD/GBP and oil price; between CERI and oil price (Daily: 4/1/2000 - 30/12/2009) 

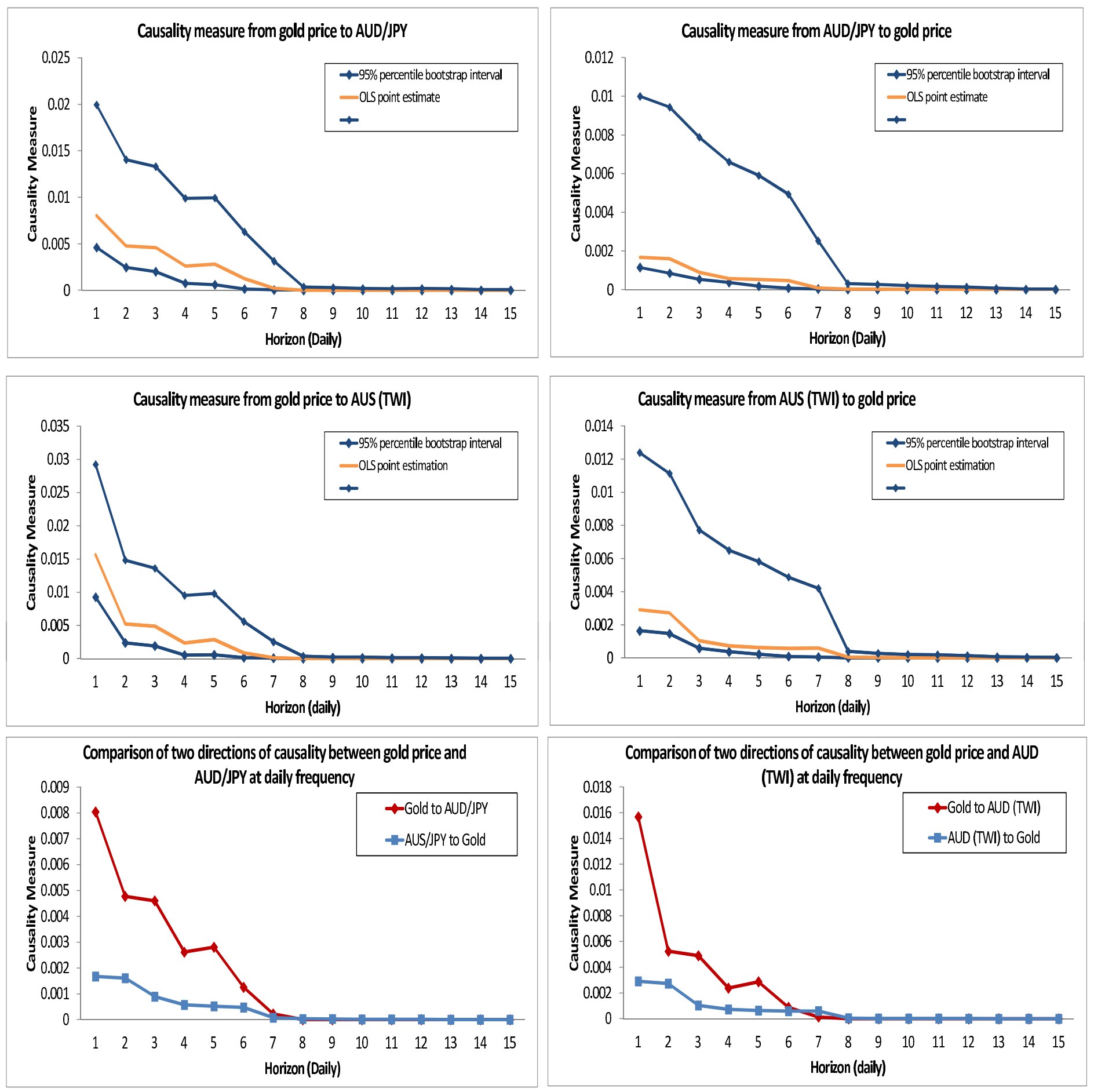

Figure 10. Unconditional causality measures between AUD/JPY and gold price; between AUD (TWI) and gold price (Daily: 4/1/2000 - 30/12/2009) 

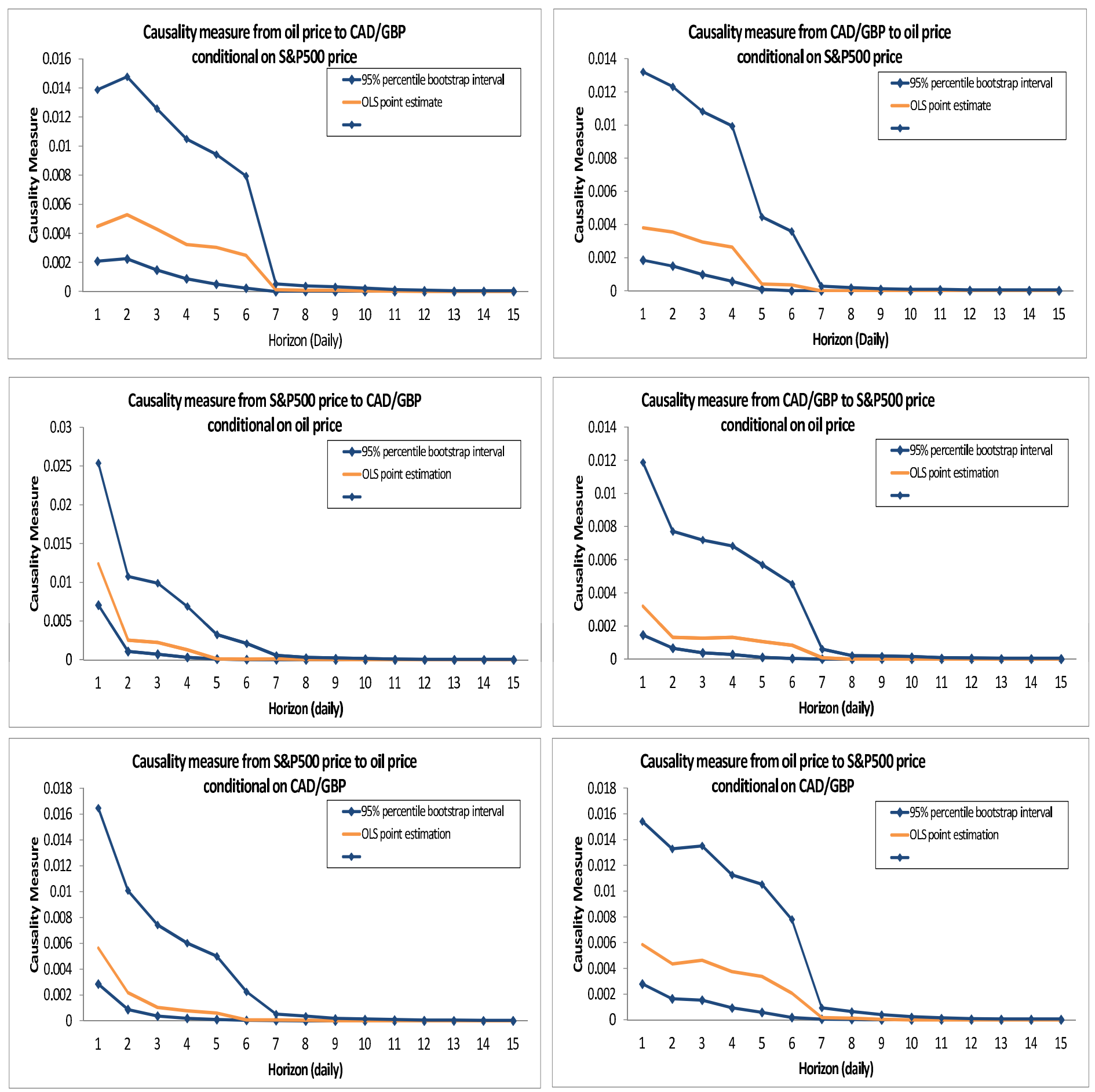

Figure 11. Conditional causality measures between CAD/GBP, oil price and S\&P500 price (Daily: 4/1/2000 - 30/12/2009) 

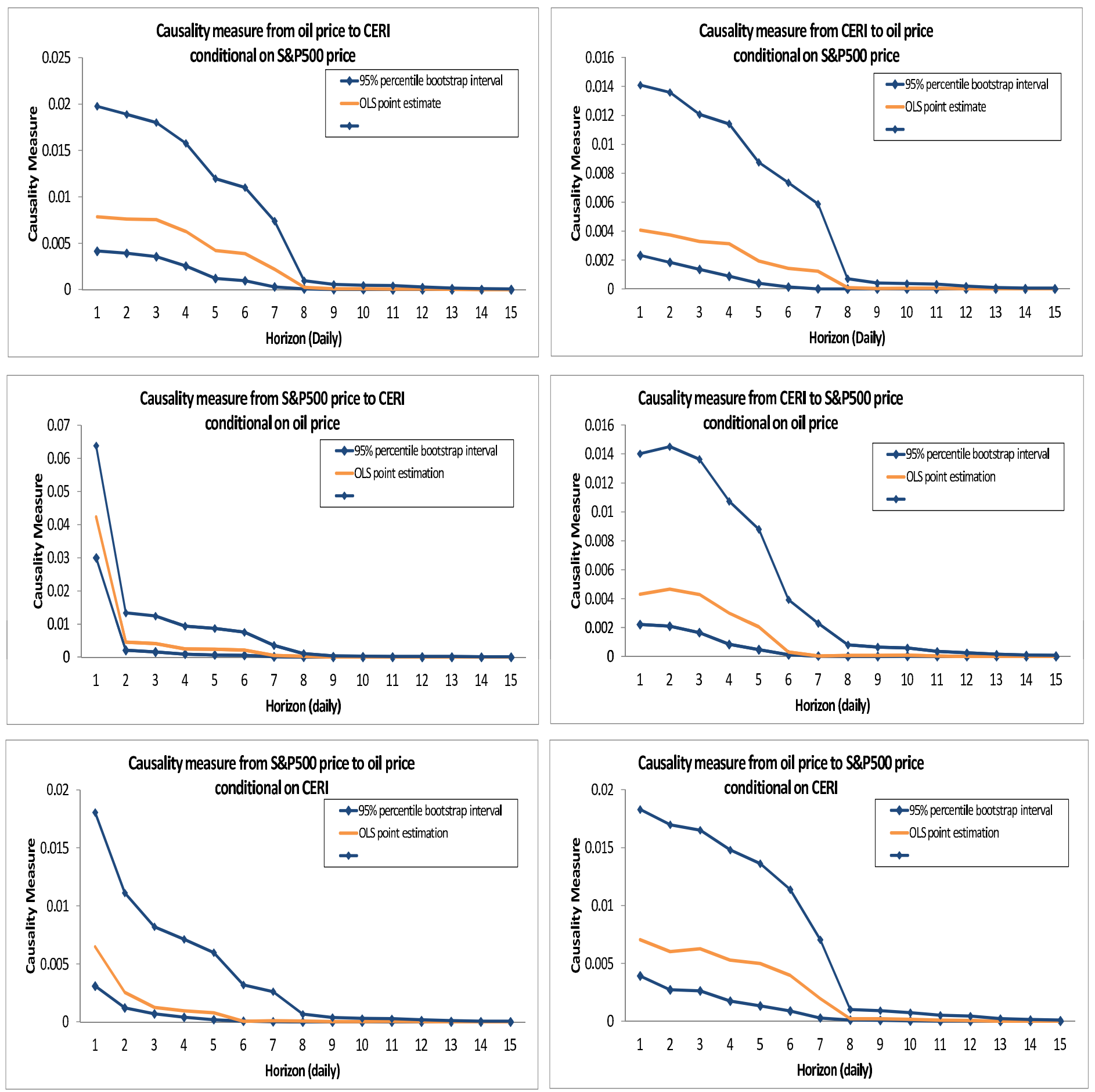

Figure 12. Conditional causality measures between CERI, oil price and S\&P500 price

(Daily: 4/1/2000 - 30/12/2009) 

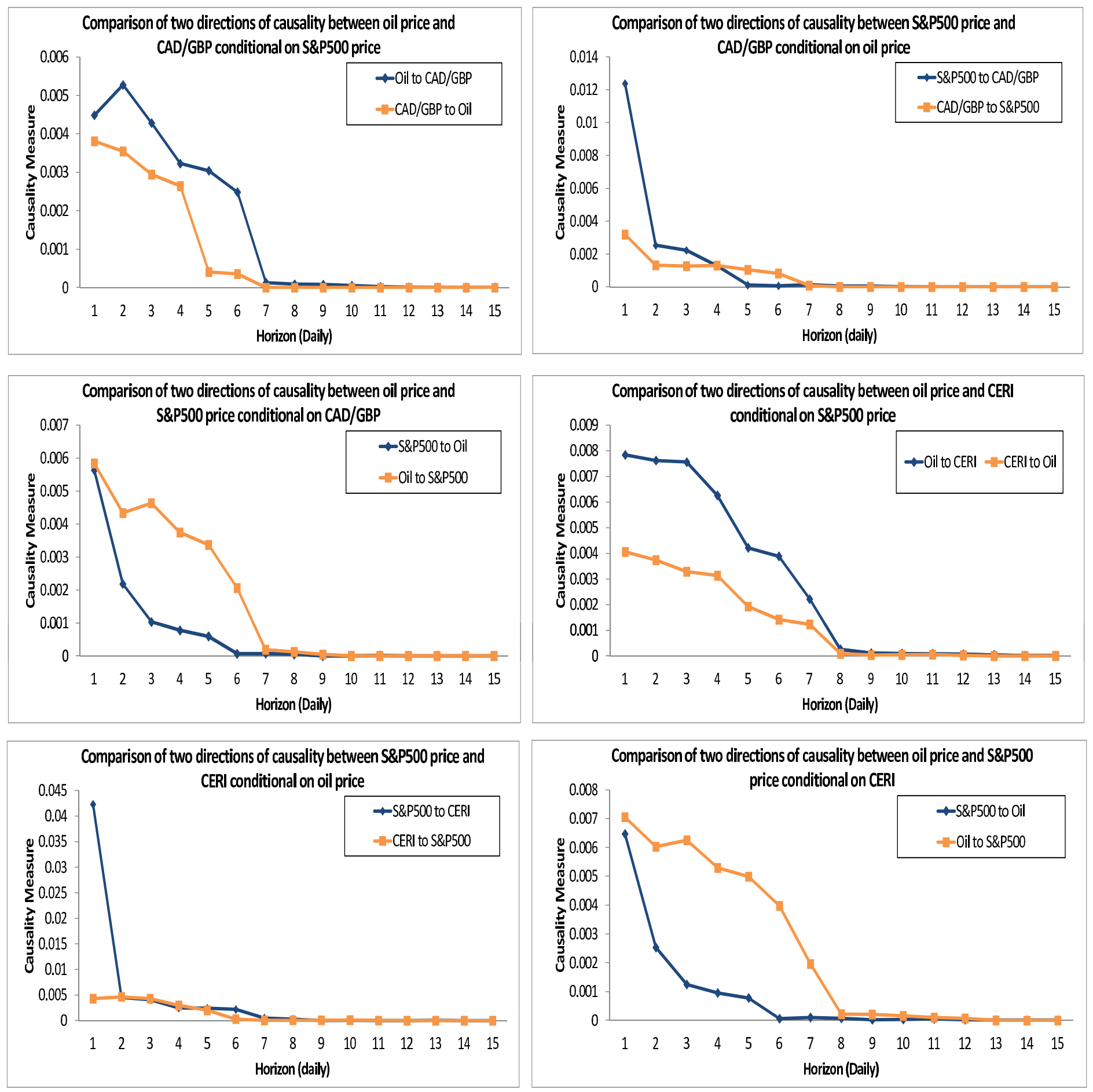

Figure 13. Comparison of two directions of causality between CAD/GBP, oil price and S\&P500 price; between CERI, oil price and S\&P500 price (Daily: 4/1/2000 - 30/12/2009) 

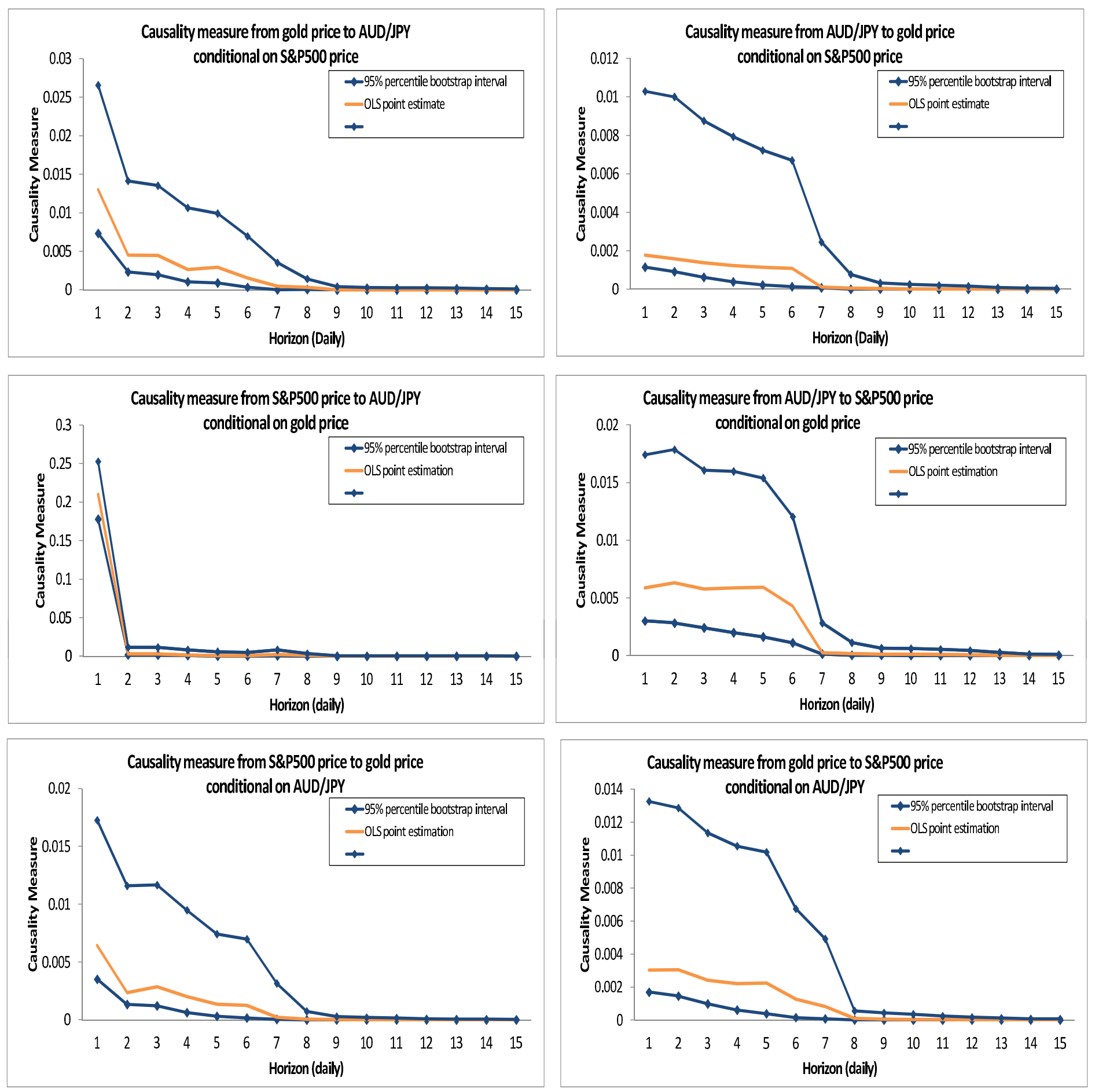

Figure 14. Conditional causality measures between AUD/JPY, gold price and S\&P500 price (Daily: 4/1/2000 - 30/12/2009) 

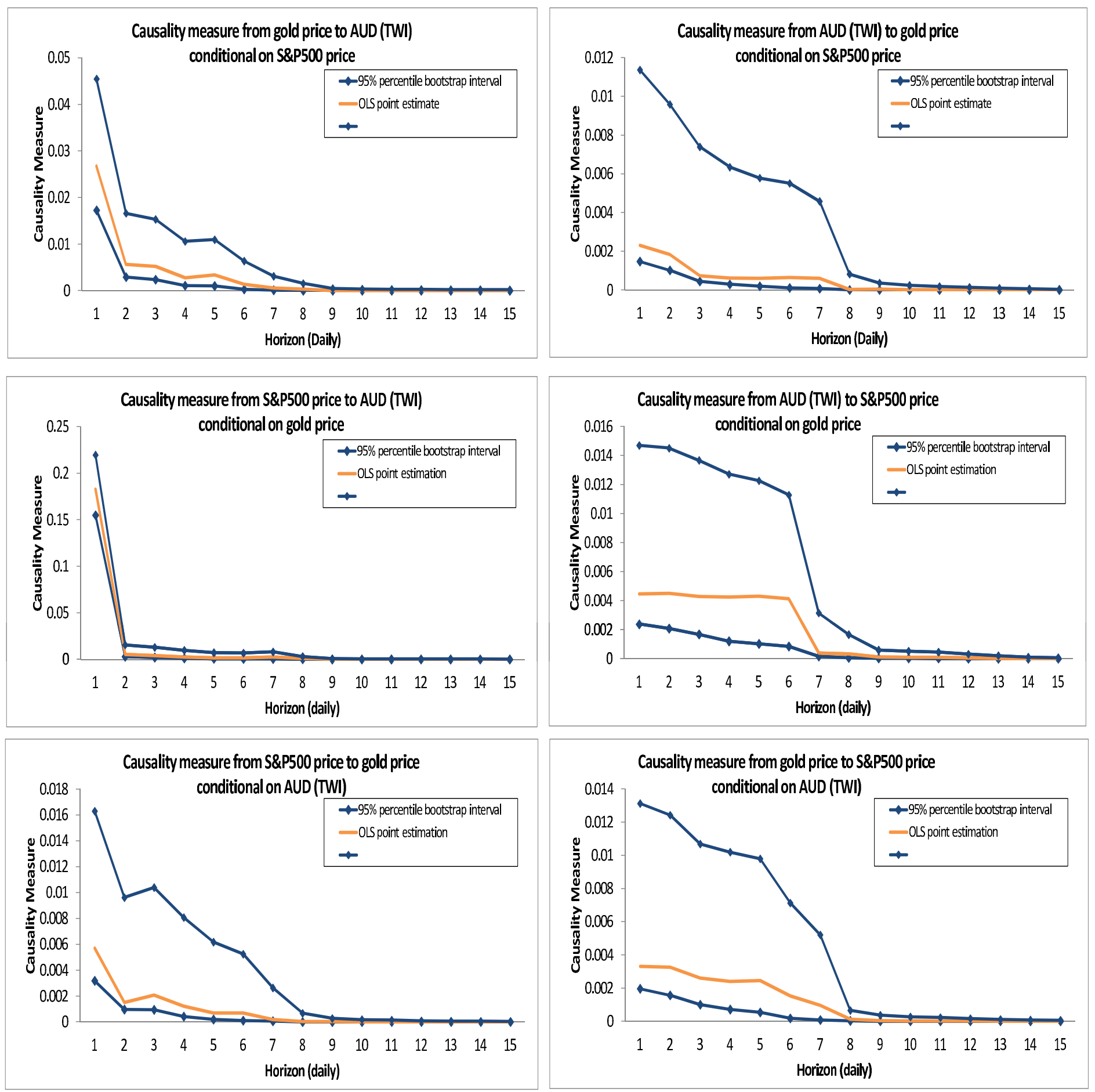

Figure 15. Conditional causality measures between AUD (TWI), gold price and S\&P500 price (Daily: 4/1/2000 - 30/12/2009) 

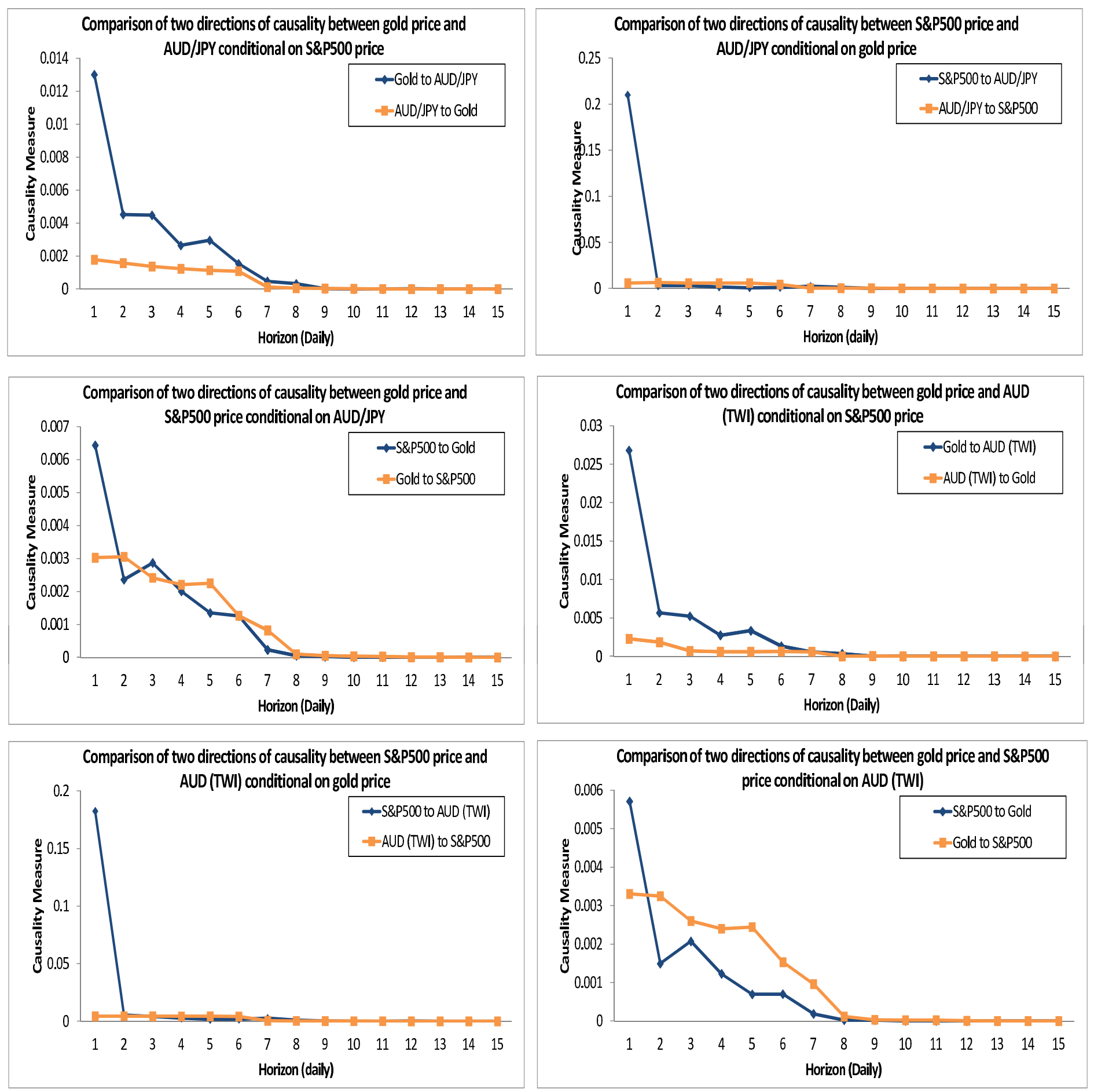

Figure 16. Comparison of two directions of causality between AUD/JPY, gold price and S\&P500 price; between AUD (TWI), gold price and S\&P500 price (Daily: 4/1/2000 - 30/12/2009) 